\title{
CARACTERIZAÇÃO AMBIENTAL DA PORÇÃO SUBAÉREA DE PRAIAS ARENOSAS EXPOSTAS COM DIFERENTES CARACTERÍSTICAS MORFODINÂMICAS NO LITORAL CENTRO-NORTE DE SANTA CATARINA, BRASIL
}

\author{
ALVES' ${ }^{1}$, E.S.; RODRIGUES ${ }^{24}$, S. DE A.; PEZZUTO³, P. R. \& G.Y. SHIMIZU² \\ ${ }^{1}$ Doutorado em Ecologia, Instituto de Biociências, Universidade de São Paulo, SP, \\ lialves@lycos.com; \\ ${ }^{2}$ Departamento de Ecologia, Instituto de Biociências, Universidade de São Paulo, SP, \\ yuka@ib.usp.br \\ ${ }^{3}$ Centro de Ciências Tecnológicas da Terra e do Mar, Universidade do Vale do Itajaí, \\ SC, pezzuto@univali.br;
}

${ }^{4}$ in memoriam

RESUMO

\begin{abstract}
A caracterização e o acompanhamento temporal de variáveis ambientais de relevante importância na determinação da estrutura das assembléias macrofaunais foram efetuadas na porção subaérea de três praias arenosas expostas do litoral centro-norte de Santa Catarina, sujeitas a regimes de micro-maré e variando de estágios dissipativo a refletivo. Amostragens realizadas entre março/2000 e março/2001 revelaram que as características ambientais disponíveis para o estabelecimento e desenvolvimento da macrofauna bentônica nas praias estudadas foram bastante particulares e estiveram relacionadas com seu estágio modal. A praia de Navegantes (dissipativa), esteve sujeita a reduzidas variações morfológicas e sedimentares durante o ano, e caracterizou-se pela presença de uma ampla zona de surfe e de espraiamento de ondas. Com gradiente suave, apresentou grande homogeneidade sedimentar ao longo do perfil e esteve composta por areias finas, moderadamente bem selecionadas a bem selecionadas, com elevados teores de umidade associados a superficialidade do lençol freático. A praia de Taquaras (refletiva) caracterizou-se pela ausência de zona de surfe e pelo predomínio de ondas do tipo ascendente/ frontal, cuja dissipação de energia ocorreu diretamente sobre a face de praia. Apresentou declividade acentuada, estreita zona de espraiamento de ondas e profundidades elevadas para o lençol freático. Esteve composta por areia grossa moderadamente bem selecionada a bem selecionada com reduzido teor de umidade, e apresentou as maiores variações espaciais e temporais nas características sedimentares e morfológicas. A praia Brava (intermediária), esteve composta por areias médias moderadamente bem selecionadas a bem selecionadas, e apresentou características intermediárias com relação a extensão das zonas de surfe e espraiamento de ondas, profundidade do lençol freático, teor de umidade do sedimento e intensidade das alterações sedimentares e morfológicas. De modo geral, o comportamento temporal das variáveis ambientais não apresentou sazonalidade e foi particular para cada uma das praias estudadas tendo decorrido das características hidrodinâmicas, sedimentares e morfológicas associadas com cada estágio morfodinâmico.
\end{abstract}

Palavras-chave: morfodinâmica, caracterização ambiental, praia arenosa, Brasil. 


\title{
ENVIRONMENTAL CHARACTERIZATION OF THE SUBAEREAL SECTOR OF EXPOSED SANDY BEACHES WITH DIFFERENT MORPHODYNAMIC CHARACTERISTICS IN THE CENTER-NORTHERN LITTORAL OF SANTA CATARINA STATE, BRAZIL
}

\begin{abstract}
The characterization and temporal monitoring of environmental variables significant to the structure of beach macrobenthic assemblages were carried out in the subaereal sector of three microtidal and exposed sandy beaches varying from dissipative to reflective conditions in the Center-Northern littoral of Santa Catarina. Monthly samples conducted between March 2000 and March 2001 showed that the environmental characteristics which are important to the development of the beach macrofauna were very distinct among the beaches and were related to their respective modal stages. Few morphological and sedimentary changes occurred along the year in Navegantes beach (dissipative), which was characterized by having wide surf and swash zones. Showing a gentle slope, Navegantes beach profile had homogeneous sediments composed by fine and moderately sorted sands with high moisture contents associated to its superficial water table. On the other hand, Taquaras beach (reflective) showed no surf zone and was dominated by surging/collapsing breakers whose energy dissipated directly on the beach face. Compared to the other beaches, Taquaras revealed the highest spatial and temporal changes in its sedimentary and morphological features and was characterized by a steep slope, narrow swash zone and deep water table. Its sediments were composed by moderately well sorted to well sorted coarse sands with reduced moisture contents. Brava beach (intermediate) was composed by moderately well sorted to well sorted medium sands and showed an intermediate pattern in terms of surf and swash zone extension, water table depth, sediment moisture and intensity of sedimentary and morphological changes. In general, the temporal behavior of the environmental variables was not seasonal along the study period and was specific for each beach, as a consequence of distinct hydrodynamic, sedimentary and morphological features associated to each morphodynamic stage.
\end{abstract}

Key words: morphodynamic, environmental characterization, sandy beach, Brazil.

\section{INTRODUÇÃO}

As praias arenosas oceânicas constituem um dos ambientes mais dinâmicos da superfície do planeta, cujos depósitos sedimentares são ativamente re-trabalhados por ondas, correntes e marés (Short, 1999).

Embora diversos autores tenham destacado a importância das interações biológicas no controle da estrutura (Defeo \& Alava, 1995; Defeo, 1996; Defeo \& Martinez, 2003) e distribuição (Alava \& Defeo, 1991; Borzone, 1999; Alves \& Rodrigues, 2003) do macrobentos de praias arenosas, os fatores físicos são considerados a força organizadora básica na regulação deste sistema caracterizado por condições abióticas extremamente severas (Brown \& McLachlan, 1990). Sendo assim, a caracterização destes fatores e a compreensão de sua dinâmica temporal tornam-se fundamentais para a realização de estudos ecológicos em praias arenosas.

Nas praias do litoral centro-norte de Santa Catarina, estudos sobre o padrão de distribuição de sedimentos, caracterização morfodinâmica, e comportamento temporal das condições hidrodinâmicas e morfológicas têm sido extensivamente realizados (p.ex. Temme et al., 1997; Miot da Silva, 2000; Klein \& Menezes, 2001; Klein et al., 2002). Entretanto, aspectos de relevante importância na determinação da estrutura das assembléias macrofaunais, como as características do espraiamento de ondas e os gradientes de profundidade e salinidade do lençol freático, umidade, tamanho médio de grão e seleção do sedimento existentes no sentido terra-mar (cross shore) (McLachlan, 1990; McArdle \& 
McLachlan, 1992; Jaramillo et al., 1993), são ainda pouco compreendidos na região.

Desta forma, com o objetivo de caracterizar o ambiente experimentado pela macrofauna bentônica da porção subaérea de três praias arenosas expostas de Santa Catarina, este trabalho descreve e quantifica os padrões de variação temporal de todos os parâmetros ambientais supracitados. Estes resultados integram um estudo mais amplo que pretendeu investigar os efeitos temporais das alterações hidrodinâmicas, sedimentares e morfológicas de praias arenosas sujeitas a distintos regimes morfodinâmicos sobre a macrofauna bentônica nelas residentes.

\section{MATERIAL E MÉTODOS}

\section{Área de Estudo}

As praias de Taquaras, Brava e Navegantes, localizadas no litoral centro-norte de Santa Catarina ( $26^{\circ} 30^{\prime}$ 'S and $27^{\circ} 20^{\prime}$ S), foram selecionadas para este estudo (Figura 1). Com orientação similar em relação a linha de costa (N-S) e classificadas como expostas e dominadas por ondas, estas praias diferem com relação as suas características morfodinâmicas (Klein \& Menezes, 2001).

Taquaras caracteriza-se pela presença de areia grossa $(0,72$ a $0,92 \mathrm{~mm})$ e bem selecionada na face praial, e por uma pendente bastante acentuada $\left(10^{\circ}\right)$ (Menezes, 1999). Com $920 \mathrm{~m}$ de extensão, classifica-se como uma praia refletiva e encontra-se sujeita a uma grande variação morfológica ao longo do ano, podendo apresentar escarpas de $2 \mathrm{~m}$ de altura durante eventos de tempestade (Menezes, 1999; Klein \& Menezes, 2001).

Navegantes possui $10.030 \mathrm{~m}$ de extensão, pendente suave $\left(2,5^{\circ}\right.$ a $\left.3,5^{\circ}\right)$ e classificase como uma praia dissipativa, estando sujeita a uma reduzida variação morfológica ao longo do ano (Klein \& Menezes, 2001). Possui sedimento composto predominantemente por areia fina $(0,15$ a $0,19 \mathrm{~mm})$ bem selecionada, e caracteriza-se pela presença de um campo de dunas frontais bastante desenvolvido (Menezes, 1999; Klein \& Menezes, 2001). A largura média de sua zona de surfe é de $83 \mathrm{~m}$, sendo comum a presença de bancos submersos e correntes de retorno (Menezes, 1999). O rio Itajaí-açu deságua na extremidade sul desta praia e pode influenciar a qualidade da água 20 $\mathrm{km}$ ao norte de sua desembocadura (Schettini et al., 1999; Schettini, 2002).

A praia Brava possui 2.645 m de extensão, caracteriza-se por apresentar estágio intermediário e pela presença de areias médias $(0,28$ a $0,34 \mathrm{~mm})$ e moderadamente selecionadas. A declividade do perfil praial varia entre $4,5^{\circ}$ e $6,5^{\circ}$ e sua zona de surfe apresenta $68 \mathrm{~m}$ de extensão em média (Menezes, 1999; Klein \& Menezes, 2001).

O regime de maré astronômica da região é caracterizado como de micromaré do tipo misto, predominantemente semidiurno com amplitude média de 0,8 $\mathrm{m}$ (Schettini et al., 1999). Entretanto, as condições meteorológicas exercem um importante papel na dinâmica costeira regional, podendo causar sobre-elevações de até $1 \mathrm{~m}$ no nível do mar (Carvalho et al., 1996; Truccolo, 1998; Schettini et al., 1999). Ventos de nordeste predominam durante praticamente todo o ano, com aumento de importância dos ventos provenientes do quadrante sul durante o inverno e primavera como resultado do aumento da freqüência e intensidade de sistemas frontais que passam pela região (Nobre et al., 1986). Ondas de E-NE com 0,5 a $1,5 \mathrm{~m}$ de altura e período de pico de 5 a $10 \mathrm{~s}$, ocorrem predominantemente no verão e possuem altura variável entre 0,5 e 1,5 m e período de pico entre 5 e $10 \mathrm{~s}$. Ondulações de maior energia, com altura média variável entre 1,5 a $3,5 \mathrm{~m}$ e períodos de pico de 8 a $15 \mathrm{~s}$, são provenientes do quadrante S-SE (Alves \& Melo, 2001).

\section{Coleta e Análise dos Dados}

Os dados utilizados neste trabalho foram coletados entre março de 2000 e março 
de 2001, a intervalos mensais nas praias de Taquaras e Navegantes e aproximadamente bimestrais na praia Brava.

Em todas as ocasiões de coleta, os seguintes parâmetros da zona de surfe foram obtidos para as praias estudadas: salinidade e temperatura da água do mar, largura da zona de surfe, número de linhas de arrebentação e altura, período e direção de incidência de onda.

A altura média de onda foi estimada visualmente, medindo-se a diferença em altura entre a crista e a cava da onda, no momento imediatamente anterior à sua quebra, durante um período de aproximadamente 5 minutos no final de cada coleta. O período de onda foi es- timado com auxílio de um cronômetro e correspondeu a 1/10 do tempo total transcorrido para a passagem de onze cristas consecutivas em um ponto fixo na zona de surfe. Três observações foram realizadas em cada coleta para a obtenção de uma média. Estes dados foram utilizados para determinar o estágio morfodinâmico das praias através do parâmetro adimensional de Dean (Wright \& Short, 1984), de acordo com a fórmula:

$$
\Omega=H b / W s \cdot T
$$

Onde $\mathbf{H}_{\mathbf{b}}$ : altura da arrebentação; Ws: velocidade média de decantação das partículas

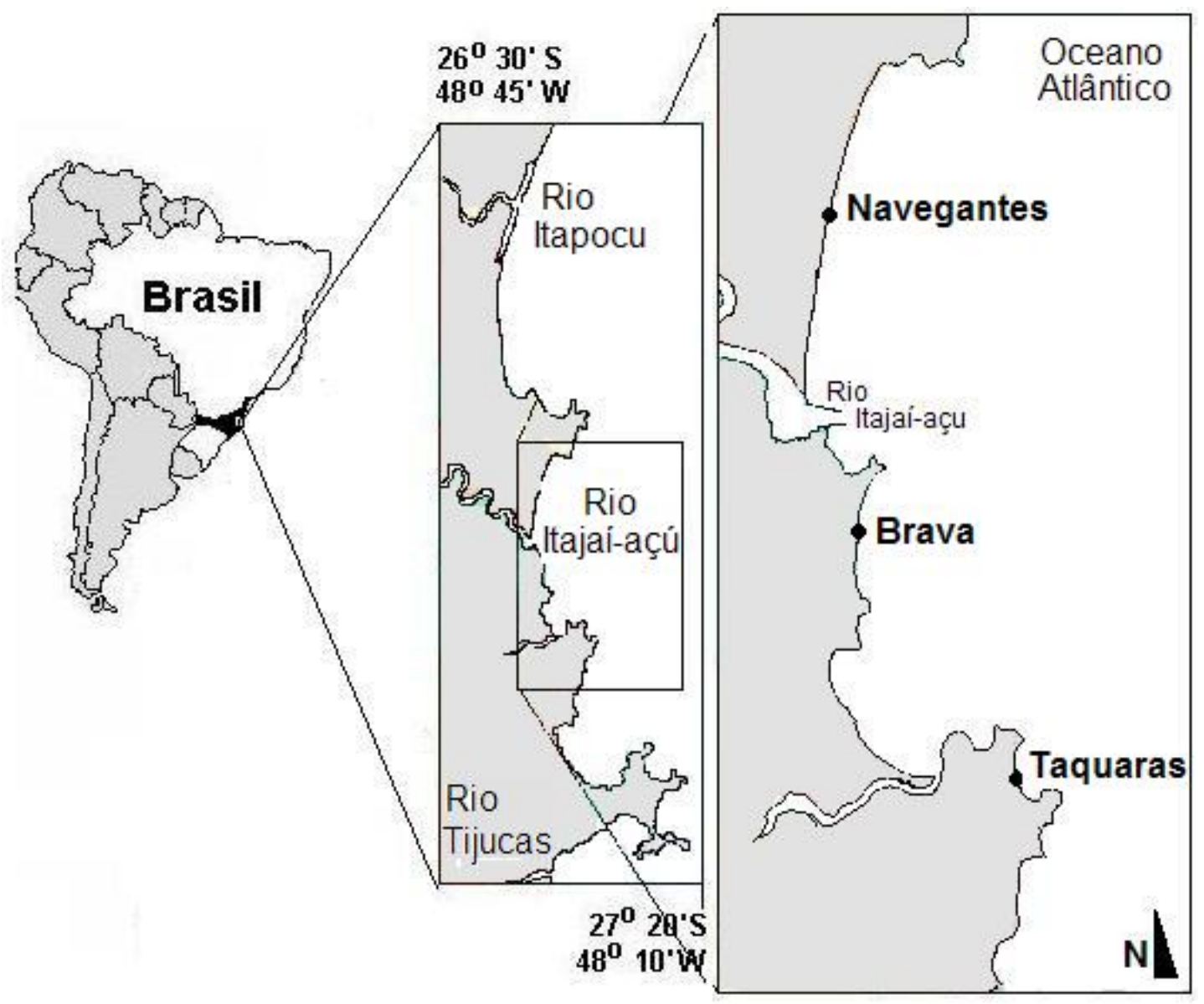

Figura 1 - Área de estudo e localização dos pontos de amostragem. 
sedimentares e T: período de onda. Valores de $\Omega<1$ indicam praias refletivas, $1<\Omega<6$ indicam praias intermediárias e $\Omega>6$ indicam praias dissipativas (Wright \& Short, 1984; Short, 1999).

Em todas as coletas, amostras de sedimento, para determinação da granulometria e do teor de umidade, foram obtidas em estações posicionadas a cada $5 \mathrm{~m}$ desde o limite da vegetação terrestre até a linha d'água (Figura 2), em uma transecção disposta na porção central de cada praia (Figura 1). De modo a manter a correspondência entre as estações em todas as ocasiões de coleta, o limite superior das mesmas foi fixado sempre a partir de um ponto fixo (RN) (Figura 2). Para a determinação do teor de umidade do sedimento, um total de três réplicas foram obtidas em cada estação de coleta com um amostrador cilíndrico de $4 \mathrm{~cm}$ de diâmetro até a profundidade de $5 \mathrm{~cm}$. O conteúdo de água foi estimado através da perda de peso do sedimento após se- cagem em estufa a $50^{\circ} \mathrm{C}$ por cerca de 48 h até a estabilização do peso das amostras. Para a análise granulométrica uma amostra de sedimento foi extraída de cada estação de coleta utilizando-se um amostrador cilíndrico de $5 \mathrm{~cm}$ de diâmetro até a profundidade de $10 \mathrm{~cm}$. As amostras foram peneiradas com intervalo de 0,5 phi e o programa computacional ANGRA (Analizador Granulométrico) (Moraes \& Griep, 1985), que tem como base o método dos momentos gráficos proposto por Folk \& Ward (1957), foi utilizado para a determinação dos parâmetros estatísticos (expressos em phi $=-\log _{2}$ diâmetro da partícula $(\mathrm{mm})$ ). Nas praias Brava e Navegantes, a análise granulométrica foi efetuada a cada duas estações de coleta (intervalos de $10 \mathrm{~m}$ ).

A profundidade e salinidade do lençol freático foram obtidos cavando-se um buraco em cada estação de coleta e medindo-se a distância entre a superfície do sedimento e a superfície do lençol freático. Durante este processo

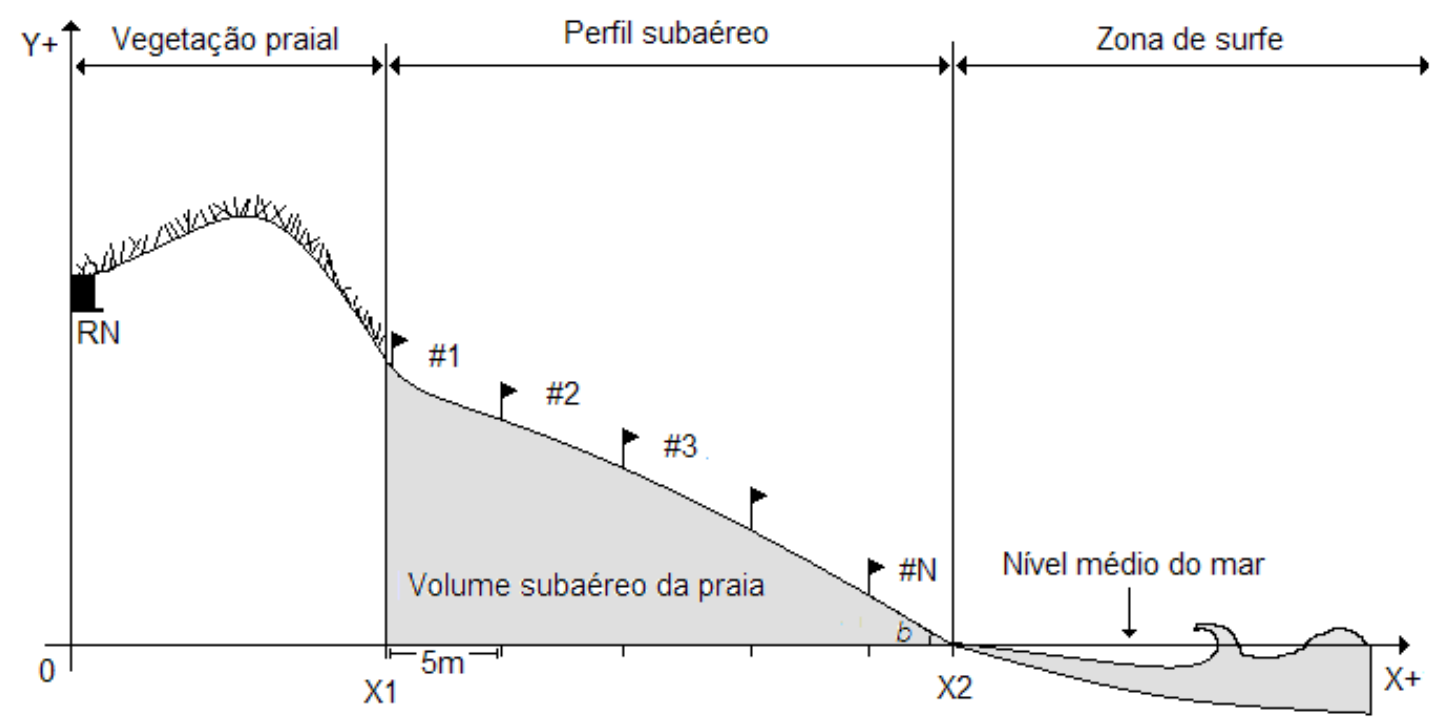

Figura 2 - Desenho esquemático do sistema de coleta. RN- Referencial de nível; \#- estação de coleta; X1- limite superior de amostragem, correspondente ao início da primeira estação de coleta e delimitado a partir do RN; X2correspondente a altura nula do perfil (cota zero) em relação ao nível médio do mar durante marés baixas de sizígia; b- declividade da face praial. Figura modificada de Temme (1996) e Temme et al. (1997). 
foi também verificada a presença ou não de camada redutora no sedimento. A salinidade do lençol freático foi obtida através da utilização de refratômetro.

Para a determinação da extensão, tempo e velocidade de subida do espraiamento de ondas, a porção subaérea das praias estudadas foi demarcada com estacas metálicas dispostas a intervalos de $1 \mathrm{~m}$ a partir da linha d'água. Estes dados foram obtidos, entre setembro de 2000 e março de 2001 , seguindo-se a metodologia proposta por McArdle \& McLachlan (1992), durante um período de aproximadamente 5 minutos para a determinação de valores médios. A extensão correspondeu a distância total (aferida com $1 \mathrm{~m}$ de precisão) percorrida pelo espraiamento de ondas entre a linha d'água e sua máxima extensão. O tempo de subida foi obtido cronometrando-se o tempo (em segundos) que a onda levou para percorrer a distância entre o nível da água e o ponto mais alto de seu espraiamento. A velocidade resultou da divisão entre a extensão e o tempo de subida do espraiamento de ondas, tendo sido expressa em $\mathrm{m} / \mathrm{s}$. Testes de correlação entre as feições do espraiamento de ondas e as características da zona de surfe (largura da zona de surfe, altura e período médios de ondas), inclinação da face praial (b) e condição morfodinâmica $(\Omega)$ foram efetuadas através do coeficiente de correlação de Pearson (Zar, 1996).

A localização do limite inferior e superior do espraiamento de ondas e da linha de deposição correspondente a marca da última maré alta (drift line) foi verificada em cada ocasião de coleta, medindo-se a distância em metros de cada um destes limites até o início do perfil praial (X1) (Figura 2).

A morfologia praial foi obtida, em todas as ocasiões de coleta, através do método de estádia idealizado por Birkemeier (1981), que consiste na medição de cotas em diferentes níveis da praia com o auxílio de um nível e régua graduada. Para permitir a comparação entre perfis consecutivos, todas as leituras foram efetuadas com base em um referencial de nível
(RN) existente na porção posterior de cada praia (Figura 2). O programa computacional ISRP (Interactive Survey Reduction Program) (Birkemeier, 1986) foi utilizado para o processamento dos dados e geração dos perfis praiais. $O$ tratamento posterior dos dados foi efetuado utilizando-se o programa BMAP (Beach Morphology Analysis Package) (CERC, 1981), o qual permite a comparação morfológica entre perfis consecutivos e o cálculo de mudanças de volume de sedimento para distâncias comuns a dois perfis. O volume total da porção sub-aérea do perfil foi calculado para cada ocasião de coleta e comparado temporalmente. Para tanto, considerou-se o trecho de praia compreendido entre o limite $\mathrm{X} 1$, correspondente ao início da primeira estação de coleta, e o limite X2, correspondente a altura nula do perfil (cota zero) em relação ao nível médio do mar durante marés baixas de sizígia (Figura 2).

A presença/ausência de feições morfológicas como escarpas pronunciadas e cúspides praias foram verificadas para cada ocasião de coleta. Quando presentes, as cúspides praiais tiveram a distância entre duas cristas consecutivas obtidas com o auxílio de uma trena. Todas as coletas foram realizadas durante marés baixas de sizígia.

\section{RESULTADOS}

\section{Características da Zona de Surfe}

A variação temporal da temperatura da água do mar foi similar para as praias estudadas. As menores temperaturas foram detectadas no inverno e as maiores no verão, evidenciando uma marcada sazonalidade neste parâmetro (Figura 3A). Por outro lado, a salinidade da água do mar apresentou flutuações temporais pronunciadas apenas em Navegantes, onde foi geralmente menor do que nas demais praias consideradas (Figura 3B).

A praia de Navegantes caracterizou-se pela presença de uma extensa zona de surfe 

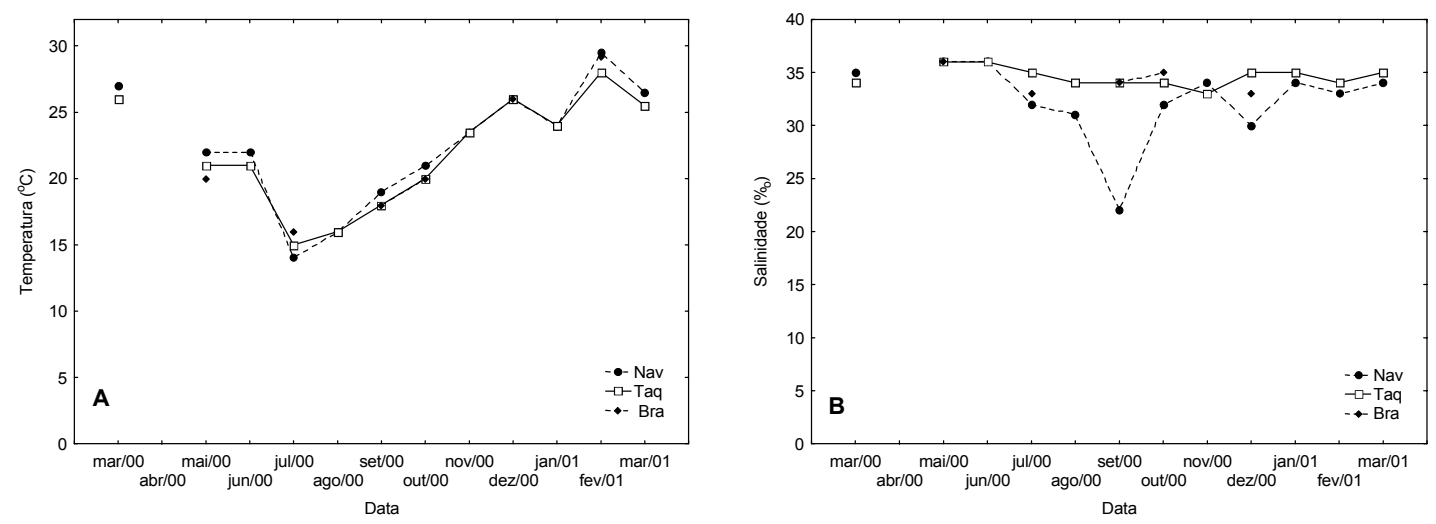

Figura 3 - Variação temporal da temperatura $(A)$ e salinidade $(B)$ da água do mar na zona de surfe das praias de Navegantes (Nav), Brava (Bra) e Taquaras (Taq), entre março de 2000 e março de 2001.

sendo freqüente a ocorrência de mais de uma linha de arrebentação de ondas (Tabela 1). Ondas do tipo deslizante e mergulhante predominaram ao longo do período de estudo, com altura significativa e período médios de $95 \mathrm{~cm}$ e 7,6 s, respectivamente. Embora acentuadas oscilações temporais nos valores de $\Omega$ tenham sido verificadas, a praia de Navegantes apresentou estágio morfodinâmico dissipativo durante praticamente todo o período de estudo e a declividade de sua face praial apresentou valores inferiores aos verificados para Taquaras e Brava (Tabela 1).

Na praia Brava a largura média da zona de surfe foi de $38 \mathrm{~m}$ e o número de linhas de arrebentação de ondas variou temporalmente, tendo-se verificado duas linhas entre os meses de março e julho/2000 e apenas uma linha nas demais ocasiões de coleta (Tabela 1). Ondas do tipo deslizante e mergulhante com altura significativa e período médios de $96 \mathrm{~cm}$ e 7,6 s, respectivamente, predominaram ao longo do período de estudo (Tabela 1). Esta praia caracterizou-se por apresentar estágio modal intermediário com valores de $\Omega$ variáveis entre 2,5 e 3,6 e a inclinação média de sua face praial oscilou temporalmente entre $1,8^{\circ}$ e $6,1^{\circ}$ (Tabela 1).

A praia de Taquaras caracterizou-se pela ausência de zona de surfe ao longo de praticamente todo o período de estudo e pela existên- cia de apenas uma linha de arrebentação localizada na beira d'água, onde a dissipação da energia de onda esteve concentrada. Apenas em setembro/2000 a zona de surfe atingiu 20 $\mathrm{m}$ de extensão coincidindo com os maiores valores de altura e período de onda verificados ao longo do estudo (Tabela 1). Predominaram ondas do tipo frontal e ascendente com altura significativa média de $104 \mathrm{~cm}$ e período médio de $6,4 \mathrm{~s}$. Os valores de $\Omega$ oscilaram entre $0,7 \mathrm{e}$ 1,9 ao longo do período de estudo (Tabela 1), indicando que o estágio morfodinâmico desta praia variou entre refletivo e intermediário de acordo com a classificação de Wright \& Short (1984). Entretanto, é preciso destacar que, no litoral centro-norte catarinense, praias com valores de $\Omega$ de até 1,57 foram classificadas como refletivas expostas por Menezes (1999) e Klein \& Menezes (2001). A declividade média de sua face praial $\left(9,2^{\circ}\right)$ foi superior às observadas para Navegantes e Brava, e sofreu pronunciadas variações temporais (Tabela 1).

Em cada amostragem, a direção de incidência de ondas foi idêntica em todas as praias consideradas, com ondulações de SE ocorrendo entre maio e agosto/2000 e ondulações provenientes dos quadrantes E/NE predominando nas demais ocasiões de coleta (Tabela 1). Variações sazonais definidas não foram verificadas para os parâmetros da zona de surfe. 
Tabela 1 - Parâmetros hidrodinâmicos e morfodinâmicos das praias de Navegantes, Brava e Taquaras, entre março de 2000 e março de 2001. Z.S.: largura da zona de surfe; No Arr.: número de linhas de arrebentação; T.O.: Tipo de onda conforme a classificação adotada por Galvin (1968 apud Hoefel, 1998), onde M: mergulhante, D: deslizante, A: ascendente e F: frontal; Hs: altura do 1/3 mais alto de ondas; T: período de onda; D.O.: Direção predominante de incidência de onda; $\Omega$ : condição morfodinâmica segundo a classificação proposta por Wright \& Short (1984); b: declividade da face praial; * - coleta não realizada. ${ }^{* *}$ - declividade não obtida.

\begin{tabular}{|c|c|c|c|c|c|c|c|c|c|c|c|c|c|}
\hline & \multicolumn{13}{|c|}{ Navegantes } \\
\hline & \multicolumn{7}{|c|}{2000} & \multicolumn{6}{|c|}{2001} \\
\hline & mar & mai & jun & jul & ago & set & out & nov & dez & jan & fev & mar & média \\
\hline Z.S. (m) & 70 & 70 & 50 & 50 & 35 & 100 & 70 & 60 & 40 & 35 & 30 & 50 & 54 \\
\hline $\mathrm{N}^{\circ}$ Arr. & 2 & 1 & 2 & 2 & 2 & 1 & 2 & 2 & 1 & 1 & 2 & 2 & \\
\hline T.O. & $\mathrm{D} / \mathrm{M}$ & $M$ & $\mathrm{D} / \mathrm{M}$ & $\mathrm{M}$ & $D / M$ & $D / M$ & D & D & $\mathrm{D} / \mathrm{M}$ & $\mathrm{M}$ & D & D & \\
\hline $\mathrm{Hs}(\mathrm{cm})$ & 66 & 135 & 88 & 107 & 72 & 147 & 100 & 109 & 76 & 67 & 82 & 90 & $\overline{95}$ \\
\hline $\mathrm{T}(\mathrm{s})$ & 6,4 & 8,5 & 6,9 & 7,5 & 6,1 & 10,5 & 10,8 & 6,6 & 6,7 & 8,0 & 6,9 & 6,6 & 7,6 \\
\hline D.O. & $\mathrm{E}$ & SE & SE & SE & SE & $\mathrm{E}$ & E & NE & NE & NE & $\mathrm{E}$ & $\mathrm{E}$ & \\
\hline $\operatorname{Ee}(m)$ & - & - & - & - & - & 13,7 & 11,2 & 10,9 & 7,6 & 5,4 & 10,9 & 7,9 & 9,7 \\
\hline $\mathrm{Te}(\mathrm{s})$ & - & - & - & - & - & 10,8 & 9,5 & 9,3 & 10,8 & 5,3 & 10,7 & 6,9 & 9,0 \\
\hline $\operatorname{Ve}(\mathrm{m} / \mathrm{s})$ & & & & & & 1,20 & 1,14 & 1,15 & 0,69 & 0,96 & 0,99 & 1,07 & 1,03 \\
\hline$\Omega$ & 5,9 & 9,1 & $\overline{7,3}$ & $\overline{8,2}$ & $\overline{6,8}$ & 8,1 & 5,3 & 9,5 & 6,5 & 4,8 & 6,8 & 7,9 & 7,2 \\
\hline \multirow[t]{4}{*}{$b\left(^{\circ}\right)$} & 1 & $* *$ & 1,4 & 2,4 & 1,2 & 1,6 & 1,7 & 1,6 & 1,1 & 2 & 1,1 & 1,1 & 1,4 \\
\hline & \multicolumn{13}{|c|}{ Brava } \\
\hline & \multicolumn{7}{|c|}{2000} & \multicolumn{6}{|c|}{2001} \\
\hline & mar & mai & jun & jul & ago & set & out & nov & dez & jan & fev & mar & média \\
\hline Z.S. (m) & 30 & 40 & * & 35 & * & 60 & 40 & $*$ & 35 & * & 25 & * & 38 \\
\hline $\mathrm{N}^{\circ}$ Arr. & 2 & 2 & * & 2 & * & 1 & 1 & * & 1 & * & 1 & * & - \\
\hline T.O. & $\mathrm{D} / \mathrm{M}$ & $\mathrm{D} / \mathrm{M}$ & * & M & * & $\mathrm{D} / \mathrm{M}$ & $\mathrm{M}$ & * & D & * & $\mathrm{D} / \mathrm{M}$ & * & \\
\hline $\mathrm{Hs}(\mathrm{cm})$ & 105 & 102 & * & 98 & * & 115 & 103 & * & 83 & * & 66 & * & $\overline{96}$ \\
\hline $\mathrm{T}(\mathrm{s})$ & 6,7 & 8,5 & * & 8,8 & * & 8,3 & 8,5 & * & 6,5 & * & 6,1 & * & 7,6 \\
\hline D.O. & $\mathrm{E}$ & SE & * & SE & * & $E$ & NE & * & $\mathrm{NE}$ & * & $E$ & * & \\
\hline $\mathrm{Ee}(\mathrm{m})$ & - & - & * & $\longrightarrow$ & - & 6,9 & 11,1 & * & 4,8 & * & 6,4 & * & 7,3 \\
\hline $\operatorname{Te}(\mathrm{s})$ & - & - & * & - & - & 7,4 & 7,5 & * & 4,9 & * & 4,8 & * & 6,1 \\
\hline$V e(\mathrm{~m} / \mathrm{s})$ & 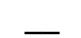 & 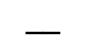 & * & & & 0,93 & 1,46 & * & 0,95 & * & 1,33 & * & 1,17 \\
\hline$\Omega$ & 3,6 & 2,7 & * & 2,5 & * & 3,2 & 2,8 & * & 2,9 & * & 2,5 & * & 2,9 \\
\hline \multirow[t]{4}{*}{$\mathrm{b}\left({ }^{\circ}\right)$} & 1,8 & 4,8 & * & 5,7 & * & 4,1 & 2,4 & * & 6,1 & * & 4,7 & * & 4,2 \\
\hline & \multicolumn{13}{|c|}{ Taquaras } \\
\hline & \multicolumn{7}{|c|}{2000} & \multicolumn{6}{|c|}{2001} \\
\hline & mar & mai & jun & jul & ago & set & out & nov & dez & jan & fev & mar & média \\
\hline Z.S. (m) & 0 & 0 & 0 & 0 & 0 & 20 & 0 & 0 & 0 & 0 & 0 & 0 & 2 \\
\hline $\mathrm{N}^{\circ}$ Arr. & 1 & 1 & 1 & 1 & 1 & 1 & 1 & 1 & 1 & 1 & 1 & 1 & - \\
\hline T.O. & $A / F$ & $\mathrm{M}$ & $A / F$ & $A / F$ & $\mathrm{M} / \mathrm{F}$ & $\mathrm{M}$ & $\mathrm{M} / \mathrm{F}$ & $\mathrm{M}$ & $\mathrm{M} / \mathrm{F}$ & $\mathrm{M} / \mathrm{F}$ & $\mathrm{M} / \mathrm{F}$ & $\mathrm{M}$ & \\
\hline $\mathrm{Hs}(\mathrm{cm})$ & 59 & 125 & 66 & 49 & 109 & 183 & 77 & 125 & 88 & 143 & 88 & 137 & 104 \\
\hline $\mathrm{T}(\mathrm{s})$ & 6,0 & 7,0 & 6,3 & 5,7 & 6,6 & 10,3 & 5,0 & 5,2 & 4,5 & 7,8 & 5,2 & 6,8 & 6,4 \\
\hline D.O. & $E$ & SE & SE & SE & SE & $E$ & $\mathrm{E}$ & NE & NE & NE & $E$ & $E$ & \\
\hline $\operatorname{Ee}(m)$ & - & - & - & - & - & 9,3 & 5,4 & 6,1 & 3,4 & 7,3 & 4,0 & 5,1 & 5,8 \\
\hline $\mathrm{Te}(\mathrm{s})$ & - & - & - & - & - & 5,0 & 4,4 & 4,9 & 3,6 & 4,0 & 3,0 & 4,2 & 4,2 \\
\hline $\mathrm{Ve}(\mathrm{m} / \mathrm{s})$ & - & - & - & - & - & 1,88 & 1,20 & 1,25 & 0,91 & 1,91 & 1,34 & 1,37 & 1,41 \\
\hline$\Omega$ & 0,8 & 1,4 & $\overline{0,8}$ & $\overline{0,7}$ & $\overline{1,3}$ & 1,4 & 1,2 & 1,9 & 1,6 & 1,5 & 1,4 & 1,6 & 1,3 \\
\hline $\mathrm{b}\left({ }^{\circ}\right)$ & 8,7 & 12,8 & 10,4 & 15,4 & 9,0 & 3,5 & 4,7 & 9,8 & 8,0 & 5,8 & 13,3 & 3,6 & 9,2 \\
\hline
\end{tabular}


Características da Zona de Espraiamento de Ondas

A extensão e o tempo de subida do espraiamento diminuíram do extremo dissipativo para o refletivo, enquanto a velocidade média sofreu um leve incremento no mesmo sentido (Tabela 1).

Considerando todas as praias estudadas, a extensão e o tempo de subida do espraiamento de ondas estiveram inversamente correlacionados com a declividade da face praial $(P<0,05)$ e positivamente correlacionados $(P<0,05)$ com o período de onda, condição morfodinâmica e largura da zona de surfe (Tabela 2). Assim, a medida que o período de onda aumenta e/ou as praias estudadas tornam-se dissipativas com zonas de surfe mais amplas e declividade menos acentuada, o espraiamento das ondas tende a ser mais extenso e a permanecer mais tempo sobre a face praial no seu percurso de subida. Por outro lado, a velocidade de subida do espraiamento de ondas tendeu a aumentar em decorrência do incremento nas condições de energia de onda $(r=0,68$; $P<0,05)$, e em menor grau em função do estabelecimento de condições morfodinâmicas mais refletivas $(r=-0,45 ; P>0,05)$ (Tabela 2$)$.

A localização da zona de espraiamento de ondas e da linha de deposição, ao longo do perfil das praias estudadas, variou temporalmente (Figura 4).
Na praia de Navegantes, a zona de espraiamento de ondas representou em média $27,5 \%$ do comprimento total do perfil da praia ( $57 \mathrm{~m}$ em média) e se deslocou em até $30 \mathrm{~m}$ ao longo do perfil praial sem apresentar, no entanto, qualquer comportamento sazonal de variação. A maior proximidade desta zona com as dunas ocorreu em setembro/2000 (Figura 4A). A região localizada acima da linha de deposição (atingida apenas pelo spray das ondas) representou $10,8 \%$ do comprimento total do perfil da praia, em média. Embora tenha atingido as dunas apenas em setembro/2000, a linha de deposição esteve localizada nas proximidades desta feição morfológica durante todo o período de estudo (Figura 4A), indicando que o retrabalhamento por ondas ocorre potencialmente ao longo de praticamente todo o perfil desta praia. Durante as coletas, parte substancial do perfil desta praia $(61,7 \%)$ esteve representada pela região compreendida entre o limite superior do espraiamento de ondas e a linha de deposição (Figura 4A).

Na praia Brava, a zona de espraiamento de ondas representou em média $22,1 \%$ do comprimento total do perfil da praia e deslocou-se temporalmente em até $20 \mathrm{~m}$ ao longo do perfil praial. Nesta praia, a região localizada acima da linha de deposição apresentou em média $28 \%$ do comprimento total do perfil (41 $\mathrm{m}$ em média) e tendeu a aumentar em extensão nos meses de verão (Figura 4B). A região

Tabela 2 - Matriz de correlação entre as feições de espraiamento de ondas (extensão, tempo e velocidade de subida) e parâmetros morfodinâmicos e da zona de surfe nas praias de Taquaras, Brava e Navegantes, entre março de 2000 e março de 2001. Hs: altura do 1/3 mais alto de ondas; T: período de onda; $\Omega$ : condição morfodinâmica segundo a classificação proposta por Wright \& Short (1984); B: declividade da face praial; Z.S.: largura da zona de surfe; N: número de observações; Os valores em destaque representam correlações significativas $(P<0,05)$.

\begin{tabular}{llllll}
\hline \hline & \multicolumn{5}{c}{ Navegantes + Brava + Taquaras (N=18) } \\
\hline \multirow{2}{*}{ Tempo de subida } & Hs & $\mathrm{T}$ & $\Omega$ & $\mathrm{B}$ & Z.S. \\
\cline { 2 - 6 } Extensão & $-0,03$ & $\mathbf{0 , 4 8}$ & $\mathbf{0 , 8 3}$ & $\mathbf{- 0 , 7 3}$ & $\mathbf{0 , 8 1}$ \\
Velocidade de subida & 0,35 & $\mathbf{0 , 7 2}$ & $\mathbf{0 , 6 5}$ & $\mathbf{- 0 , 6 6}$ & $\mathbf{0 , 7 8}$ \\
& $\mathbf{0 , 6 8}$ & 0,29 & $-0,45$ & 0,20 & $-0,31$ \\
\hline
\end{tabular}



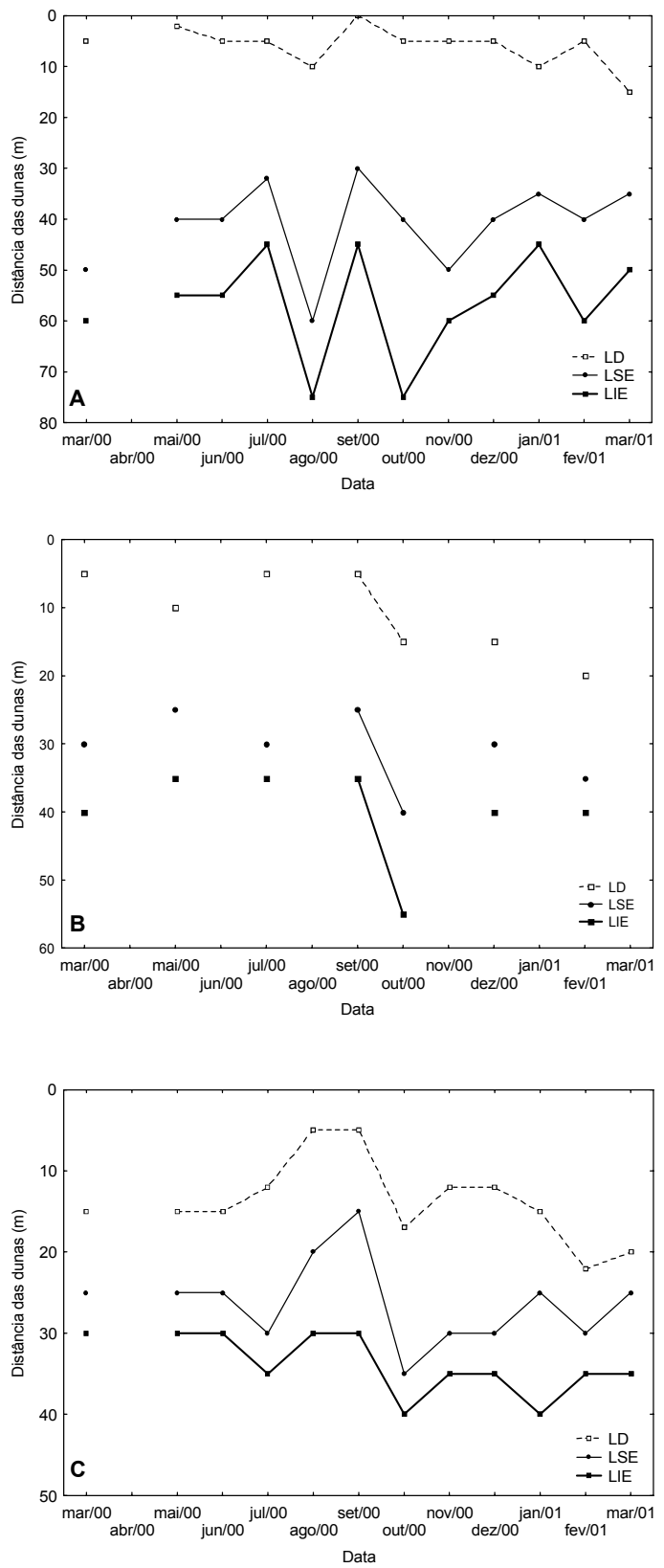

Figura 4 - Localização mensal da linha de deposição (LD) e do limite superior (LSE) e inferior (LIE) do espraiamento de ondas ao longo do perfil das praias de Navegantes (A), Brava (B) e Taquaras (C), entre março de 2000 e março de 2001. A distância "0" corresponde ao início da primeira estação de coleta no limite com as dunas e/ou vegetação praial. localizada entre o limite superior do espraiamento de ondas e a linha de deposição na praia Brava representou em média 49,8\% do comprimento total do perfil da praia.

Em Taquaras, a região de espraiamento de ondas representou em média $22,4 \%$ do comprimento total do perfil da praia (34 m em média) (Figura 4C). A região localizada acima da linha de deposição foi proporcionalmente maior do que aquelas observadas para Navegantes e Brava, tendo representado em média $40,5 \%$ do comprimento total do perfil da praia. Com exceção dos meses de agosto e setembro/2000, ocasiões em que esteve localizada a $5 \mathrm{~m}$ do início da praia, a linha de deposição manteve-se sempre a mais de $15 \mathrm{~m}$ deste local, indicando que o retrabalhamento por ondas nesta porção do perfil praial é reduzido ou inexistente durante parte do ano. O afastamento progressivo desta linha em relação a vegetação de praia foi verificado de setembro/ 2000 para março/2001 (Figura 4C), acompanhando a acresção do perfil. A região compreendida entre o limite superior do espraiamento de ondas e a linha de deposição foi proporcionalmente menor nesta praia, se comparada com as demais, tendo representado $36,1 \%$ do comprimento total do perfil praial (Figura 4).

\section{Morfologia Praial}

A magnitude da remobilização sedimentar esteve inversamente correlacionada com a condição morfodinâmica das praias estudadas ( $r=-0,65 ; P<0,01 ; N=31)$, intensificando-se ao longo do gradiente dissipativo-refletivo.

O volume de sedimento da porção subaérea das praias tendeu a aumentar ao longo do período de estudo, excetuando uma redução pronunciada verificada em setembro/2000 para as praias Brava e de Taquaras. Nesta última praia, o incremento temporal no volume de sedimento foi bem mais acentuado, principalmente, a partir de outubro/2000 (Figura 5).

A praia de Navegantes apresentou um volume médio de sedimento na porção subaérea 
de $40,4 \mathrm{~m}^{3} / \mathrm{m}$ e caracterizou-se por apresentar as menores alterações morfológicas observadas neste estudo, com variações verticais máximas de 0,68 m no pacote de sedimento, considerando-se todo o período de estudo (Figura 6A). De modo geral, a magnitude da remobilização sedimentar foi semelhante nos diferentes níveis da praia e nenhum período de erosão/acresção intenso foi identificado durante o período monitorado. Cúspides praiais pouco acentuadas, com extensão variável entre 10 m e 20 m, foram verificadas em apenas $25 \%$ das coletas.

Com um volume médio de sedimento de $48,4 \mathrm{~m}^{3} / \mathrm{m}$ na porção subaérea, a praia Brava apresentou níveis intermediários de remobilização sedimentar se comparada com as demais praias, tendo-se verificado variações verticais de até $1,31 \mathrm{~m}$ em seu pacote de sedimento (Figura 6B). Ao contrário do verificado para Navegantes, a magnitude do retrabalhamento variou ao longo do perfil praial. Enquanto nos níveis superiores da praia (primeiros dez metros) a morfologia praial permaneceu praticamente inalterada ao longo do período de estudo, variações pronunciadas foram verificadas no restante do perfil praial (Figura $6 \mathrm{~B})$. Cúspides praiais, possuindo entre 20 e 30

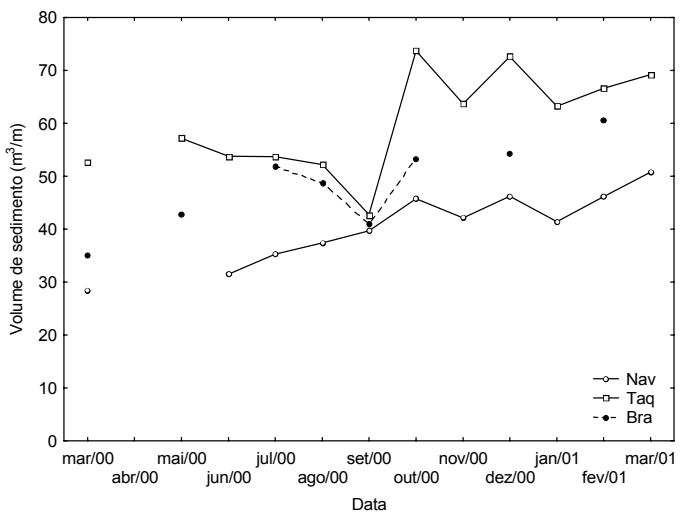

Figura 5 - Variação temporal do volume de sedimento da porção sub-aérea das praias de Navegantes (Nav), Brava (Bra) e Taquaras (Taq), entre março de 2000 e março de 2001.
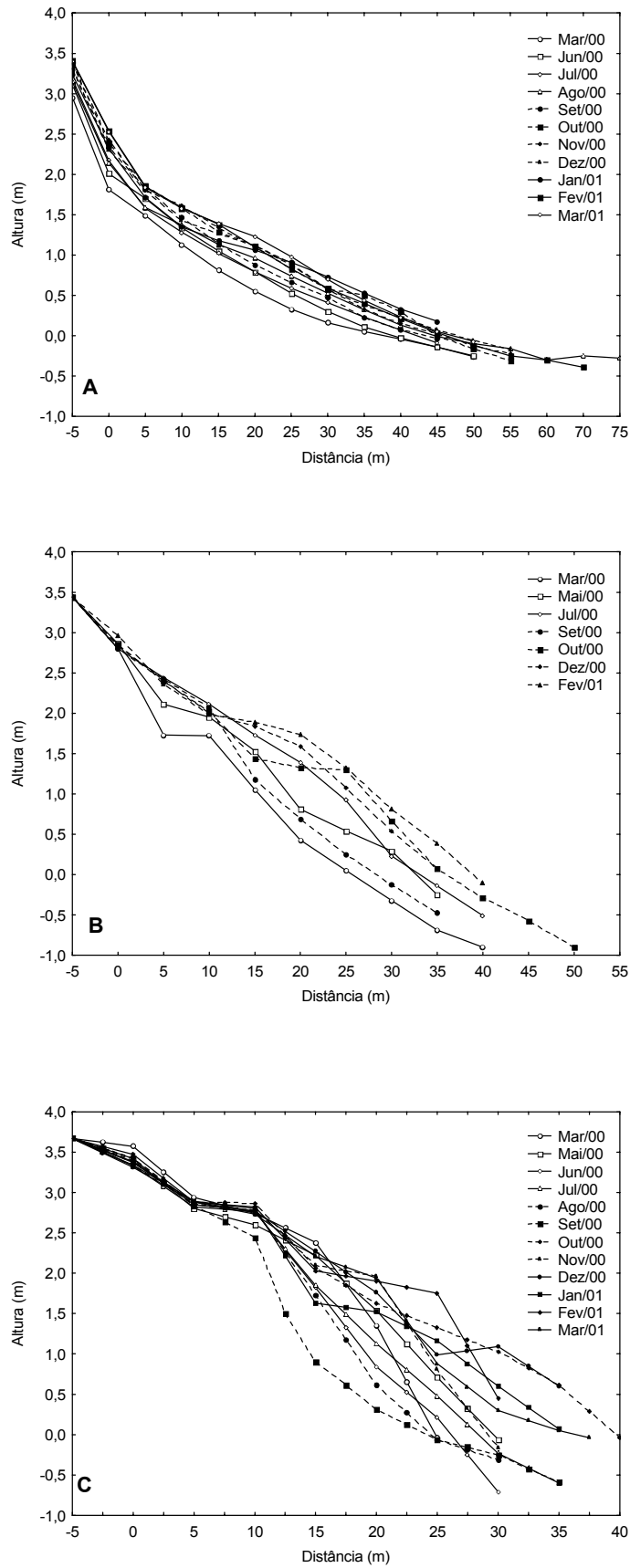

Figura 6 - Variação temporal do perfil topográfico da porção sub-aérea das praias de Navegantes (A), Brava (B) e Taquaras (C), entre março de 2000 e março de 2001. A distância "0" corresponde ao início da primeira estação de coleta no limite com a vegetação praial. 
m de extensão, foram observadas em $57 \%$ das coletas realizadas nesta praia.

As maiores alterações morfológicas foram observadas para a praia de Taquaras, onde variações verticais de até 1,90 m ocorreram no pacote sedimentar ao longo do período de estudo (Figura 6C). O volume médio de sedimento na sua porção subaérea foi de $60 \mathrm{~m}^{3} / \mathrm{m} \mathrm{e}$, assim como na praia Brava, os níveis superiores do perfil praial (primeiros quinze metros) praticamente não apresentaram variações temporais na morfologia. Apenas em setembro/ 2000 uma acentuada erosão foi observada em níveis mais superiores do perfil praial (Figura 6C). Na praia de Taquaras, a presença de cúspides praiais (com extensão variável entre 15 e 25 m) e escarpas pronunciadas foram observadas durante $58 \%$ e $16 \%$ das ocasiões de coleta, respectivamente.

\section{Características Sedimentares}

As praias estudadas apresentaram sedimento unimodal com areias moderadamente bem selecionadas a bem selecionadas, e diferiram quanto ao tamanho médio de grão e quanto aos padrões espaciais e temporais de variação da composição e seleção granulométrica.

A praia de Navegantes caracterizou-se pela presença de areia fina (Tabela 3) e moderadamente bem selecionada a bem selecionada (Tabela 4), ao longo do período de estudo. Embora sedimentos mais grosseiros tenham sido ocasionalmente observados nos níveis mais próximos da linha d'água, o tamanho médio de grão mostrou-se bastante homogêneo ao longo do perfil praial, tendo apresentado em média 2,54 phi $(0,17 \mathrm{~mm})$ e 2,53 phi $(0,19 \mathrm{~mm})$ no nível mais superior e inferior desta praia, respectivamente. Variações temporais um pouco mais acentuadas no tamanho de grão foram observadas apenas na porção mais inferior do perfil praial, onde o coeficiente de variação foi de 7,9 \% (Tabela 3). De modo geral, o grau de seleção dos grãos diminuiu em direção a linha d'água, onde eventualmente verifi- cou-se a presença de sedimentos moderamente bem selecionados. A intensidade das variações temporais no grau de seleção do sedimento aumentou na mesma direção (Tabela 4).

A praia Brava esteve composta predominantemente por areias médias com 1,7 a 1,38 phi $(0,31$ a 0,38 mm) (Tabela 3), moderadamente bem selecionadas na face praial e bem selecionadas no restante do perfil (Tabela 4). De modo geral, o tamanho médio de grão tendeu a aumentar em direção às extremidades do perfil (Tabela 3), enquanto o grau de selecionamento tendeu a diminuir, principalmente, na direção a linha d'água (Tabela 4). No entanto, variações expressivas nestes padrões foram observadas temporalmente. As variações temporais no tamanho médio de grão e grau de seleção tenderam a aumentar progressivamente dos níveis superiores para os inferiores da praia, sendo a magnitude destas variações superiores àquelas verificadas para a praia de Navegantes (Tabelas 3 e 4).

A praia de Taquaras esteve composta por areia grossa (Tabela 3), moderadamente bem selecionada a bem selecionada (Tabela 4) e caracterizou-se por apresentar as maiores variações espaciais e temporais na composição e seleção granulométrica detectadas neste estudo (Tabelas 3 e 4). O tamanho médio de grão variou de 0,92 phi $(0,53 \mathrm{~mm})$ do nível mais superior para 0,52 phi $(0,71 \mathrm{~mm})$ no nível mais inferior desta praia. No entanto, variações expressivas neste padrão foram observadas temporalmente. A composição granulométrica foi temporalmente mais estável nos $10 \mathrm{~m}$ iniciais da praia, onde coeficientes de variação inferiores a $10 \%$ foram observados (Tabela 3 ). No restante do perfil praial, coeficientes de variação variáveis entre 22 e 68,7 \% foram verificados, indicando alterações temporais expressivas no tamanho de grão (Tabela 3). Um padrão semelhante foi observado para o grau de seleção do sedimento embora com coeficientes de variação menos acentuados (Tabela 4). 
NOTAS TÉC. FACIMAR, 8: 1-24, 2004.

Tabela 3 - Variação mensal do tamanho médio de grão (phi) ao longo do perfil das praias de Taquaras, Brava e Navegantes, entre março de 2000 e março de 2001. Dist. (m): indica a distância a partir do início da primeira estação de coleta no limite com a vegetação praial; C.V.: coeficiente de variação (\%); * - coleta não realizada.

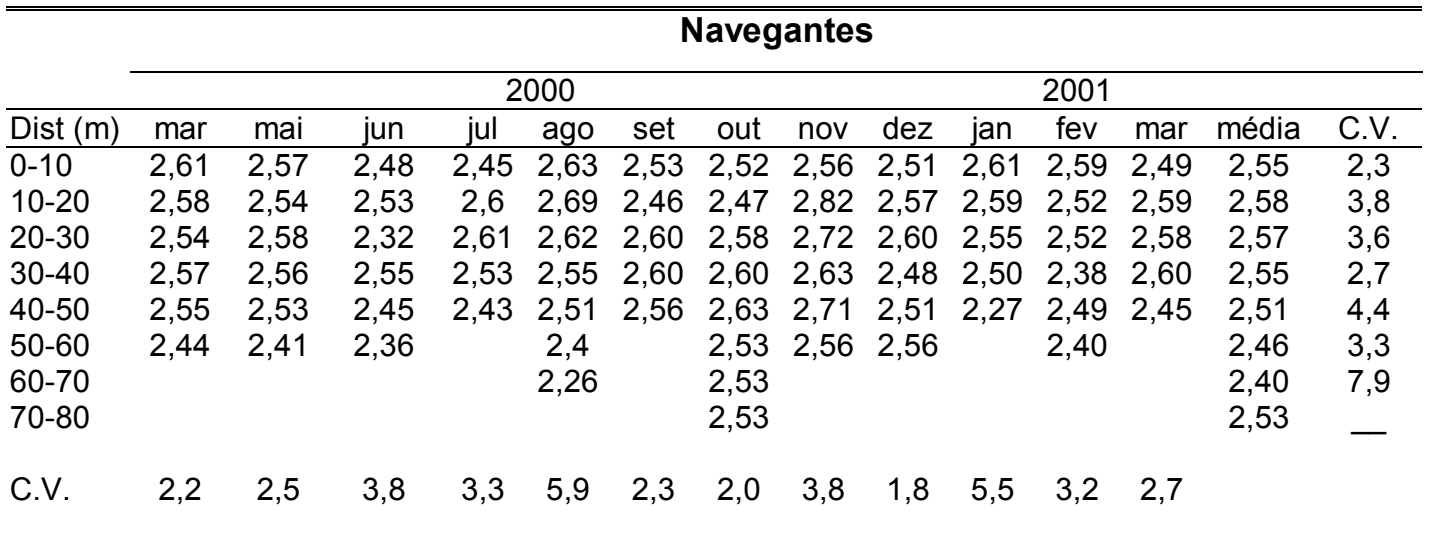

Brava

\begin{tabular}{|c|c|c|c|c|c|c|c|c|c|c|c|c|c|c|}
\hline & & & \multicolumn{5}{|c|}{2000} & \multicolumn{7}{|c|}{2001} \\
\hline Dist $(\mathrm{m})$ & mar & mai & jun & jul & ago & set & out & nov & dez & jan & fev & mar & média & C.V. \\
\hline $0-10$ & 1,57 & 1,65 & * & 1,69 & * & 1,69 & 1,68 & * & 1,74 & * & 1,76 & * & 1,70 & 2,2 \\
\hline $10-20$ & 1,70 & 1,93 & * & 1,79 & * & 1,75 & 1,85 & * & 1,86 & * & 1,87 & * & 1,86 & 3,7 \\
\hline $20-30$ & 1,55 & 1,94 & * & 1,96 & * & 1,91 & 1,74 & * & 1,83 & * & 2,01 & * & 1,91 & 4,8 \\
\hline $30-40$ & 1,41 & 1,98 & * & 1,99 & * & 1,89 & 1,85 & * & 1,47 & * & 1,97 & * & 1,89 & 10,3 \\
\hline $40-50$ & & & * & & * & & 1,86 & * & & * & & * & 1,86 & - \\
\hline $50-60$ & & & * & & * & & 1,38 & * & & * & & * & 1,38 & - \\
\hline C.V. & 7,6 & 8,1 & * & 7,7 & * & 5,9 & 10,7 & * & 10,3 & * & 5,9 & * & & \\
\hline
\end{tabular}

\section{Taquaras}

\begin{tabular}{lcccccccccccccc} 
& \multicolumn{1}{c}{2000} & \multicolumn{1}{c}{2001} \\
\hline Dist $(\mathrm{m})$ & mar & mai & jun & jul & ago & set & out & nov & dez & jan & fev & mar & média & C.V. \\
\hline $0-5$ & 0,94 & 0,90 & 0,89 & 0,91 & 0,91 & 0,94 & 0,89 & 0,91 & 0,97 & 0,92 & 0,90 & 1,03 & 0,93 & 4,4 \\
$5-10$ & 0,71 & 0,71 & 0,83 & 0,76 & 0,89 & 0,69 & 0,67 & 0,85 & 0,82 & 0,78 & 0,75 & 0,68 & 0,76 & 9,6 \\
$10-15$ & 0,98 & 0,83 & 1,01 & 0,69 & 0,74 & 0,37 & 0,81 & 1,01 & 0,92 & 0,62 & 0,70 & 0,81 & 0,79 & 23,4 \\
$15-20$ & 0,94 & 0,66 & 0,77 & 0,81 & 0,66 & 0,85 & 0,78 & 0,92 & 0,53 & 0,31 & 0,87 & 0,50 & 0,72 & 26,7 \\
$20-25$ & 0,97 & 0,93 & 0,59 & 0,80 & 0,65 & 0,82 & 0,43 & 0,87 & 0,79 & 0,45 & 0,92 & 0,29 & 0,71 & 31,6 \\
$25-30$ & 0,73 & 0,66 & 0,51 & 0,79 & 0,56 & 0,67 & 1,03 & 0,79 & 0,62 & 0,55 & 0,93 & 0,84 & 0,72 & 22,0 \\
$30-35$ & & & & 0,62 & & & 0,90 & 0,63 & 0,29 & 0,16 & 0,78 & 0,72 & 0,59 & 45,5 \\
$35-40$ & & & & & & & 0,78 & & & 0,27 & & & 0,53 & 68,7
\end{tabular}

$\begin{array}{lllllllllllll}\text { C.V. } & 14,1 & 15,5 & 24,4 & 12,1 & 19,1 & 27,7 & 22,8 & 14,0 & 34,1 & 51,5 & 10,9 & 34,7\end{array}$

Profundidade do Lençol Freático e Teor de Umidade do Sedimento

Na praia de Navegantes, em decorrência da inclinação suave (Tabela 1), o lençol freático apresentou profundidades reduzidas se comparadas com as demais praias estudadas, localizando-se bem perto da superfície em parte substancial do perfil praial, onde profundidades médias de no máximo $20 \mathrm{~cm}$ foram verificadas (Figura 7A). Nesta praia, as variações temporais mais expressivas na profundi- 
ALVES et al.: Caracterização ambiental de praias expostas.

Tabela 4 - Variação mensal do grau de seleção do sedimento (phi) ao longo do perfil das praias de Taquaras, Brava e Navegantes, entre março de 2000 e março de 2001. Dist. (m): indica a distância a partir do início da primeira estação de coleta no limite com a vegetação praial; C.V.: coeficiente de variação (\%); * - coleta não realizada.

\begin{tabular}{|c|c|c|c|c|c|c|c|c|c|c|c|c|c|c|}
\hline \multirow[b]{3}{*}{$\begin{array}{l}\text { Dist } \\
\text { (m) }\end{array}$} & \multicolumn{14}{|c|}{ Navegantes } \\
\hline & \multicolumn{7}{|c|}{2000} & \multicolumn{7}{|c|}{2001} \\
\hline & mar & mai & jun & jul & ago & set & out & nov & dez & jan & fev & mar & média & C.V. \\
\hline $0-10$ & 0,33 & 0,38 & 0,34 & 0,38 & 0,37 & 0,38 & 0,39 & 0,35 & 0,35 & 0,36 & 0,38 & 0,36 & 0,36 & 5,17 \\
\hline $10-20$ & 0,35 & 0,36 & 0,37 & 0,39 & 0,35 & 0,37 & 0,36 & 0,37 & 0,37 & 0,38 & 0,4 & 0,41 & 0,37 & 5,02 \\
\hline $20-30$ & 0,41 & 0,41 & 0,49 & 0,39 & 0,4 & 0,39 & 0,39 & 0,38 & 0,38 & 0,41 & 0,41 & 0,4 & 0,41 & 7,18 \\
\hline $30-40$ & 0,38 & 0,44 & 0,4 & 0,48 & 0,43 & 0,49 & 0,4 & 0,41 & 0,41 & 0,45 & 0,47 & 0,42 & 0,43 & 8,08 \\
\hline $40-50$ & 0,37 & 0,44 & 0,46 & 0,51 & 0,46 & 0,51 & 0,43 & 0,39 & 0,39 & 0,5 & 0,46 & 0,52 & 0,45 & 11,30 \\
\hline $50-60$ & 0,4 & 0,49 & 0,53 & 0,58 & & 0,53 & 0,5 & 0,42 & 0,42 & & 0,5 & & 0,49 & 12,45 \\
\hline $60-70$ & & & & 0,53 & & 0,51 & & & & & & & 0,52 & 2,72 \\
\hline $70-80$ & & & & & & 0,53 & & & & & & & 0,53 & - \\
\hline C.V. & 2,1 & 3,2 & 5,1 & 5,5 & 3,1 & 4,9 & 3,3 & 1,8 & 1,8 & 3,9 & 3,2 & 4,0 & & \\
\hline
\end{tabular}

Brava

\begin{tabular}{llllllllllllllll} 
& \multicolumn{1}{c}{2000} & \multicolumn{1}{c}{ 2001 } \\
\hline $\begin{array}{l}\text { Dist } \\
(\mathrm{m})\end{array}$ & mar & mai & jun & jul & ago & set & out & nov & dez & jan & fev & mar & média & C.V. \\
\hline $0-10$ & 0,44 & 0,44 & $*$ & 0,42 & $*$ & 0,42 & 0,39 & $*$ & 0,41 & $*$ & 0,40 & $*$ & 0,42 & 4,1 \\
$10-20$ & 0,43 & 0,38 & $*$ & 0,41 & $*$ & 0,41 & 0,39 & $*$ & 0,38 & $*$ & 0,37 & $*$ & 0,39 & 4,9 \\
$20-30$ & 0,58 & 0,36 & $*$ & 0,40 & $*$ & 0,35 & 0,49 & $*$ & 0,39 & $*$ & 0,40 & $*$ & 0,40 & 11,6 \\
$30-40$ & 0,62 & 0,38 & $*$ & 0,51 & $*$ & 0,36 & 0,42 & $*$ & 0,53 & $*$ & 0,45 & $*$ & 0,44 & 14,6 \\
$40-50$ & & & $*$ & & $*$ & & 0,48 & $*$ & & $*$ & & $*$ & 0,55 & 18,0 \\
$50-60$ & & & $*$ & & $*$ & & 0,70 & $*$ & & $*$ & & $*$ & 0,70 & -
\end{tabular}

C.V. $18,78,9 * 11,6 * 9,124,4 * 16,2 * 8,2$ *

\section{Taquaras}

\begin{tabular}{lllllcccccccccc} 
& \multicolumn{1}{c}{2000} & \multicolumn{1}{c}{2001} \\
\hline $\begin{array}{l}\text { Dist } \\
(\mathrm{m})\end{array}$ & mar & mai & jun & jul & ago & set & out & nov & dez & jan & fev & mar & média & C.V. \\
\hline $0-5$ & 0,43 & 0,40 & 0,41 & 0,40 & 0,42 & 0,43 & 0,39 & 0,44 & 0,43 & 0,44 & 0,40 & 0,41 & 0,42 & 4,14 \\
$5-10$ & 0,44 & 0,47 & 0,46 & 0,43 & 0,4 & 0,47 & 0,48 & 0,42 & 0,38 & 0,41 & 0,43 & 0,44 & 0,44 & 7,02 \\
$10-15$ & 0,49 & 0,46 & 0,48 & 0,58 & 0,41 & 0,64 & 0,47 & 0,50 & 0,52 & 0,52 & 0,50 & 0,48 & 0,50 & 11,67 \\
$15-20$ & 0,45 & 0,61 & 0,37 & 0,36 & 0,40 & 0,36 & 0,56 & 0,48 & 0,53 & 0,50 & 0,36 & 0,37 & 0,45 & 19,93 \\
$20-25$ & 0,41 & 0,40 & 0,34 & 0,33 & 0,38 & 0,41 & 0,68 & 0,41 & 0,40 & 0,60 & 0,44 & 0,48 & 0,44 & 23,38 \\
$25-30$ & 0,51 & 0,45 & 0,38 & 0,32 & 0,47 & 0,42 & 0,55 & 0,44 & 0,36 & 0,42 & 0,45 & 0,37 & 0,43 & 15,19 \\
$30-35$ & & & & 0,39 & & & 0,42 & 0,51 & 0,50 & 0,62 & 0,48 & 0,35 & 0,47 & 19,22 \\
$35-40$ & & & & & & & 0,58 & & & 0,58 & & & 0,58 &
\end{tabular}

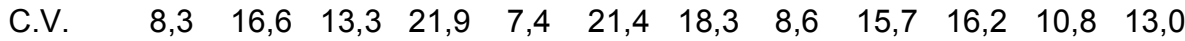

dade do lençol freático ocorreram nos primeiros $30 \mathrm{~m}$ do perfil e não apresentaram qualquer comportamento sazonal (Figura 8A). A salinidade média do lençol freático tendeu a sofrer um incremento em direção a linha d'água, embora com algumas descontinuidades (Figu- 

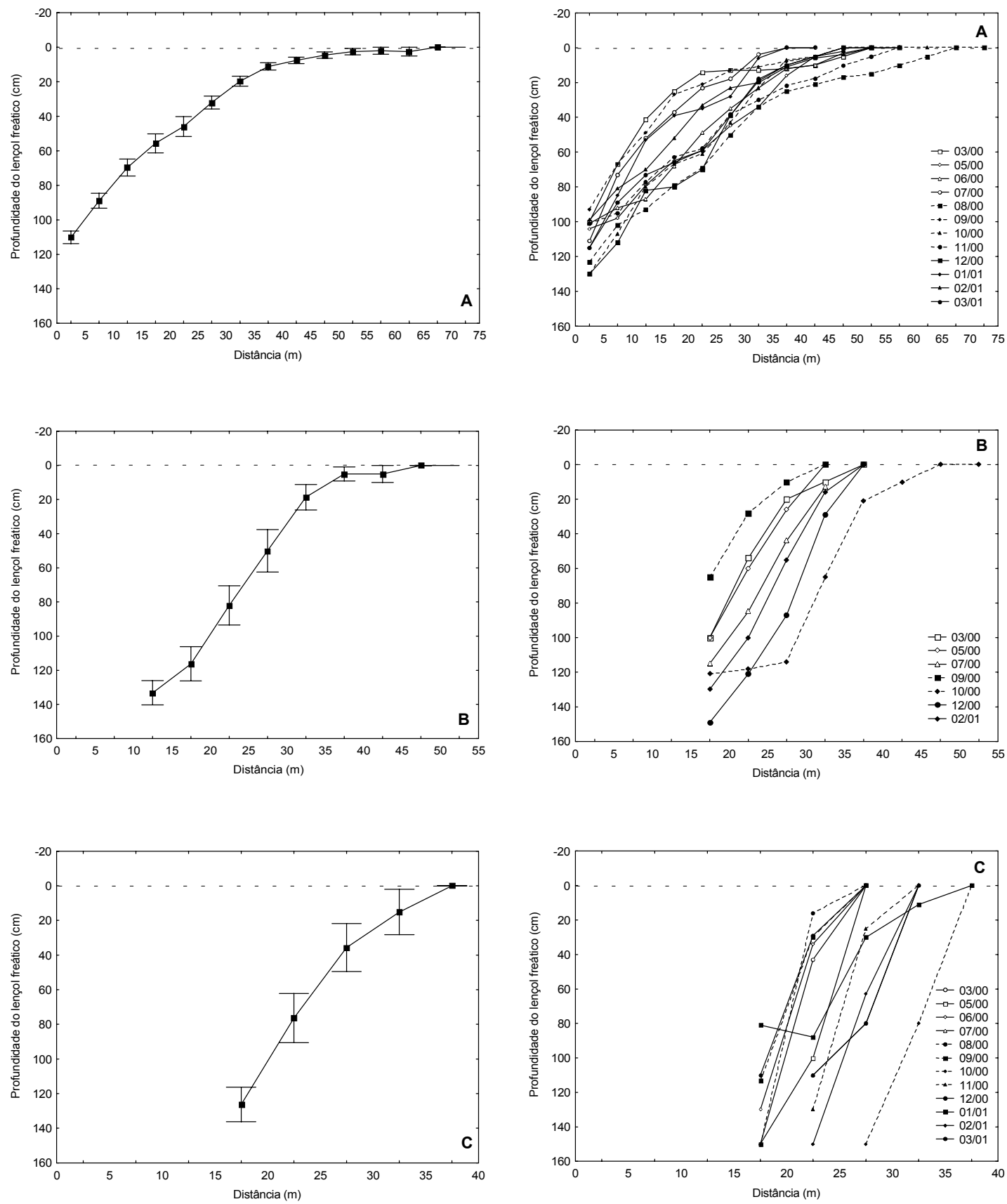

Figura 7 - Profundidade média do lençol freático (+ E.P) ao longo do perfil das praias de Navegantes (A), Brava (B) e Taquaras (C), entre março de 2000 e março de 2001. A distância "0" corresponde ao início da primeira estação de coleta no limite com a vegetação praial.

Figura 8 - Variação temporal da profundidade do lençol freático ao longo do perfil das praias de Navegantes (A), Brava (B) e Taquaras (C), entre março de 2000 e março de 2001. A distância "0" corresponde ao início da primeira estação de coleta no limite com a vegetação praial. 
ra 9A). A superficialidade do lençol freático associada com a presença de sedimento fino e extensas zonas de espraiamento de ondas condicionaram valores elevados de umidade do sedimento em Navegantes (Figura 10A).

Se comparada com as demais praias estudadas, a praia Brava caracterizou-se por apresentar valores intermediários na profundidade do lençol freático (Figura 7B) e na umidade do sedimento (Figura 10B). Profundidades inferiores a $20 \mathrm{~cm}$ foram observadas para o lençol freático apenas nos níveis próximos da água. A partir deste local, um pronunciado incremento foi observado na direção da vegetação terrestre, atingindo profundidades superiores a $150 \mathrm{~cm}$ nos $10 \mathrm{~m}$ iniciais da praia (Figura 7B). Embora este padrão tenha sido verificado durante praticamente todo o período de estudo, variações temporais expressivas foram observadas para a profundidade do lençol freático nesta praia (Figura 8B). A salinidade média do lençol freático diminuiu para os níveis superiores da praia (Figura 9B). A umidade média do sedimento foi inferior a $10 \%$ em parte significativa do perfil (Figura 10B), sendo que as maiores variações temporais ocorreram entre $15 \mathrm{e}$ $35 \mathrm{~m}$ do perfil praial (Figura 11B).

As maiores profundidades do lençol freático foram verificadas para a praia de Taquaras como resultado da inclinação acentuada de seu perfil. A profundidade média do lençol freático sofreu um acentuado incremento a partir de linha d'água e foi superior a 150 cm em parte substancial da praia (Figura 7C). Assim como na praia Brava, variações temporais pronunciadas na profundidade do lençol freático foram observadas ao longo do período de estudo nesta praia (Figura 8C). A salinidade média do lençol freático não apresentou gradientes ao longo do perfil praial onde valores superiores a $32 \%$ foram observados (Figura 9C). A umidade média do sedimento apresentou valores bastante reduzidos (geralmente inferiores a $5 \%$ ) na maior parte do perfil praial, atingindo valores máximos apenas próximo da linha d'água, na região delimitada pelo espraia-
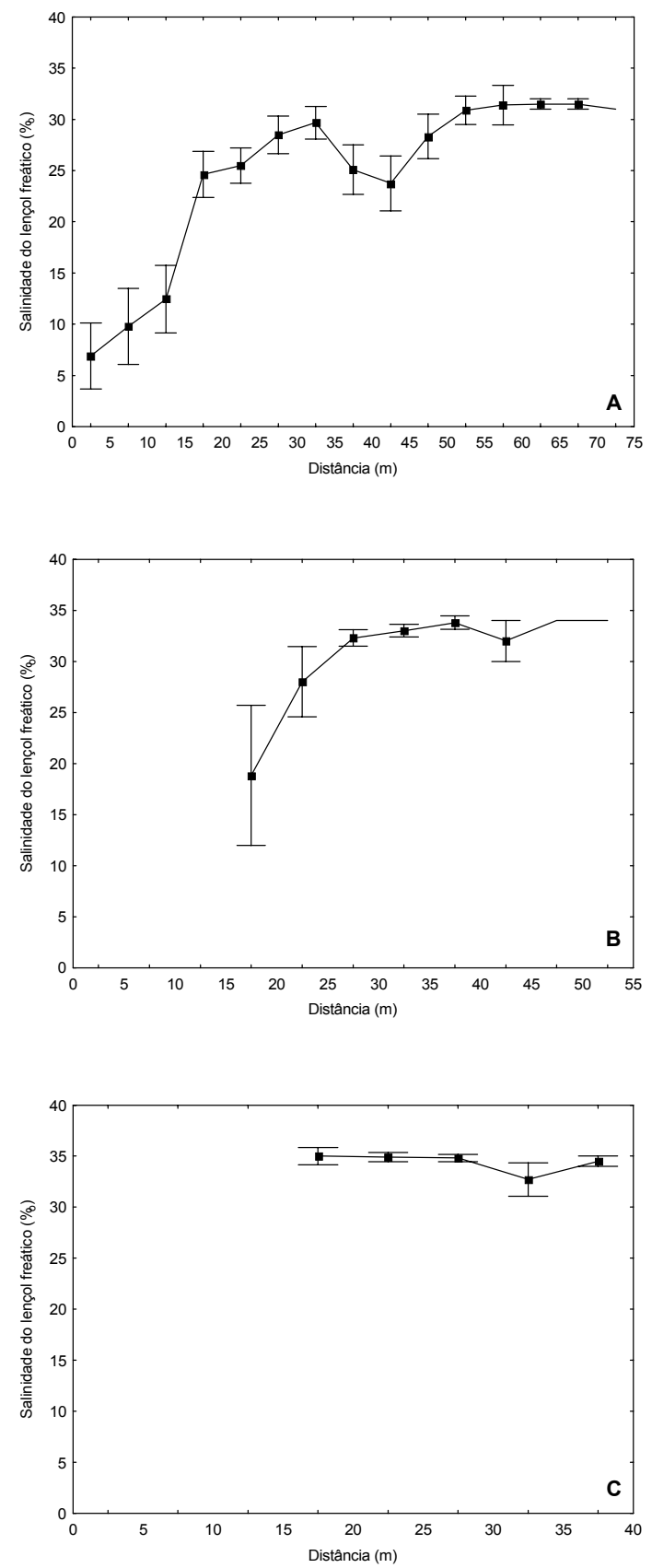

Figura 9 - Salinidade média do lençol freático (+ E.P) ao longo do perfil das praias de Navegantes (A), Brava (B) e Taquaras (C), entre março de 2000 e março de 2001. A distância " 0 " corresponde ao início da primeira estação de coleta no limite com a vegetação praial. 

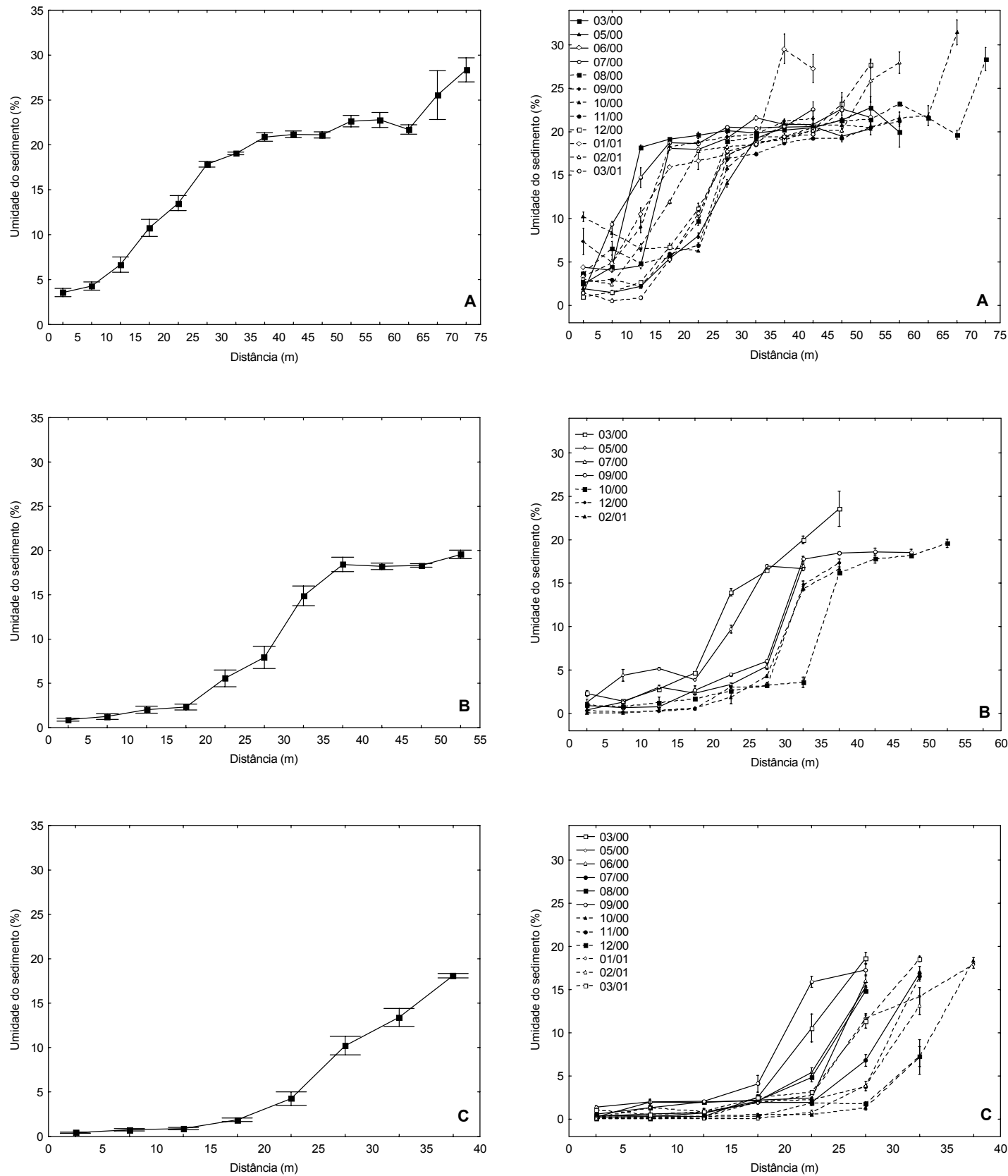

Figura 10 - Teor médio de umidade do sedimento (+ E.P) ao longo do perfil das praias de Navegantes (A), Brava (B) e Taquaras (C), entre março de 2000 e março de 2001. A distância "0"corresponde ao início da primeira estação de coleta no limite com a vegetação praial.

Figura 11 - Teor de umidade no sedimento (+ E.P) ao longo do perfil das praias de Navegantes (A), Brava (B) e Taquaras (C), nas diversas amostragens realizadas entre março de 2000 e março de 2001. A distância "0" corresponde ao início da primeira estação de coleta no limite com a vegetação praial. 
mento das ondas (Figura 10C). Tal fato persistiu durante todo o período de estudo (Figura 11C).

Em nenhuma das ocasiões de coleta verificou-se a presença de camada redutora no sedimento das praias estudadas.

\section{DISCUSSÃO}

As características ambientais disponíveis para o estabelecimento e desenvolvimento da macrofauna bentônica nas praias de Taquaras, Brava e Navegantes foram bastante particulares e estiveram relacionadas com o estágio modal de cada praia. De modo geral, o comportamento temporal das variáveis estudadas seguiu padrões distintos entre as praias, sendo que a magnitude destas variações tendeu a aumentar do extremo dissipativo para o refletivo, principalmente com relação as características morfológicas e sedimentares.

Com exceção da marcada sazonalidade observada para a temperatura da água do mar destas praias, decorrente do clima temperado característico da região (Nobre et al., 1986), não se verificou qualquer variação sazonal nos demais parâmetros estudados. Estes foram condicionados por fatores cuja ocorrência e/ou intensidade apresentaram natureza errática. Cabe destacar que o efeito destes fatores se manifestou de duas formas distintas: a) respostas isoladas de alguma praia a efeitos localizados no espaço; e b) respostas simultâneas a efeitos de grande escala espacial observados em todas as praias, porém com comportamento e magnitude variáveis de acordo com suas características específicas.

Na praia de Navegantes, os valores reduzidos de salinidade e sua acentuada flutuação temporal decorreram, provavelmente, da influência exercida pelo rio Itajaí-açu nesta região. Este rio deságua na extremidade sul da praia de Navegantes e pode causar alterações na salinidade da água $20 \mathrm{~km}$ ao norte de sua desembocadura como resultado do deslocamento da pluma fluvial sobre a plataforma continental adjacente (Schettini et al., 1999; Schettini, 2002). A dimensão e evolução da pluma são controladas pelo regime hidrológico do rio, o qual não apresenta uma sazonalidade marcada, sendo consideravelmente variável ao longo do ano (Schettini, 2002).

Embora os dados relativos a zona de surfe tenham apresentado grande variabilidade temporal, um incremento expressivo na altura de onda e largura da zona de surfe foi verificado em setembro/2000 para as praias estudadas (Tabela 1), indicando a ocorrência de um evento de alta energia na região. De fato, nesta ocasião as coletas foram realizadas sob condições de tempestade, o que não se observou nos demais meses de amostragem. Como será discutido no decorrer do texto, o referido evento parece ter condicionado alterações pronunciadas em algumas características ambientais das praias estudadas.

As diferenças nas condições do espraiamento de ondas observadas ao longo do espectro morfodinâmico (Tabela 1) podem ser explicadas pelas especificidades das características sedimentares, morfológicas e hidrodinâmicas existentes em cada praia.

Em Navegantes, onde parte da dissipação da energia de onda ocorre ainda na zona de surfe, o espraiamento tendeu a apresentar velocidades reduzidas. Por outro lado, a declividade suave do perfil associada à baixa permeabilidade do sedimento, decorrente da presença de areia fina e da superficialidade do lençol freático, resultou em espraiamentos de onda com percursos extensos e duradouros. Em Taquaras, por sua vez, a dissipação da energia de onda diretamente sobre a face praial resultou em espraiamentos de onda com velocidades um pouco mais elevadas. Porém, a declividade acentuada do perfil e a alta permeabilidade do sedimento grosseiro condicionou a existência de espraiamentos de onda curtos e pouco duradouros. Cabe ainda ressaltar que o evento de alta energia, registrado para setembro/2000, não parece ter causado alterações expressivas nas condições do espraiamento de ondas, a não ser pelo incre- 
mento pronunciado observado para a extensão do espraiamento nas praias de Navegantes e Taquaras neste período.

Segundo McArdle \& McLachlan (1992), a altura de onda e a declividade da face praial explicam a maior parte da variabilidade observada para o espraiamento de ondas ao longo do espectro morfodinâmico. A interação entre estas variáveis parece ter condicionado, ao menos em parte, os diferentes comportamentos temporais observados para cada uma das praias estudadas.

Em Navegantes, a variabilidade nas condições do espraiamento de ondas parece ter sido controlada principalmente pelas alterações na altura de onda, uma vez que nesta praia a declividade da face praial apresentou uma variação temporal muito reduzida. Por outro lado, nas praias de Taquaras e Brava, a variabilidade temporal das feições de espraiamento de ondas parece ter decorrido de interações mais complexas entre a declividade da face praial e parâmetros da zona de surfe. Isto porque nestas praias, além da variabilidade temporal na altura de ondas (que, de modo geral, apresentou correlações positivas com as feições do espraiamento), ocorreram também acentuadas alterações na declividade da face praial (que apresentou correlações negativas com as feições do espraiamento). Entretanto, considerando o número reduzido de observações efetuadas em cada praia, resultados mais conclusivos a este respeito poderão ser obtidos a partir de estudos que contemplem uma maior freqüência amostral e/ou escalas de tempo menores (dias/horas) sob condições de alteração pronunciada na energia de onda (p. ex. durante um evento de tempestade).

Neste estudo a magnitude da remobilização sedimentar aumentou do extremo dissipativo para o refletivo concordando com os trabalhos realizados por Menezes (1999), Klein \& Menezes (2001) e Klein et al. (2002) em praias da região. Verificou-se ainda a existência de padrões distintos de retrabalhamento ao longo do perfil das praias estudadas, os quais estiveram relacionados com as diferentes for- mas de dissipação da energia de onda e características morfológicas de cada praia.

No extremo dissipativo, em função da baixa declividade do perfil, espraiamentos de onda de reduzida velocidade aproximaram-se freqüentemente das dunas durante as marés altas, resultando em variações reduzidas no volume de sedimento ao longo de praticamente todo o perfil praial. Por outro lado, no extremo refletivo, em função da acentuada declividade e da alta permeabilidade do sedimento, a dissipação da energia das ondas manteve-se concentrada nos níveis intermediários e inferiores da praia, condicionando variações pronunciadas no volume de sedimento apenas nestes setores. Somente em setembro/2000, uma diminuição acentuada no volume de sedimento foi verificada a cerca de $10 \mathrm{~m}$ do início do perfil, indicando que a erosão dos níveis superiores desta praia encontra-se condicionada a ocorrência de eventos de alta energia. Embora existam poucos dados disponíveis, a praia Brava parece ter apresentado um comportamento similar ao de Taquaras.

Ao contrário do verificado em praias das costas oeste do hemisfério norte, onde existem períodos marcados de acresção e erosão no verão e inverno, respectivamente (Short, 1999), no presente estudo não se detectou uma sazonalidade definida com relação à variação no volume de sedimento e na morfologia das praias estudadas, sendo que as variações mais pronunciadas pareceram estar relacionadas com a ocorrência de eventos esporádicos de alta energia.

De acordo com Short (1999), o comportamento temporal das características morfodinâmicas de uma praia é determinado pelo clima de ondas, o qual varia regionalmente e globalmente. Neste sentido, Benedet FiIho (2000) destaca que a falta de sazonalidade observada para as praias do litoral centro-norte catarinense decorre da inexistência de ciclicidade no clima de ondas característico da costa leste da América do Sul, o qual segundo Short (1999) é dominado por ondulações dos quadrantes S/SE e E/NE com energia média a 
moderada durante todo o ano. De fato, através de observações diárias realizadas na praia Brava, Benedet Filho (2000) verificou que a altura e a direção predominante das ondas variaram significativamente ao longo do período de estudo, sem uma ciclicidade definida, indicando que eventos de alta energia de onda são imprevisíveis e podem ocorrer em qualquer mês do ano nesta região.

Embora a passagem de sistemas frontais pela região sul do Brasil seja mais freqüente durante o inverno e primavera, isto não implica necessariamente a ocorrência de eventos de alta energia de onda nas praias catarinenses. A fisiografia do litoral, caracterizada pela presença de inúmeras enseadas pouco confinadas que abrem-se para o oceano ao longo da costa (Villwock, 1987), nem sempre permite a incidência direta das ondulações sobre as praias, as quais terminam por se propagarem ao largo. Além disso, dependendo das condições de ventos atuantes, os sistemas frontais podem diminuir de intensidade e/ou desviar para o oceano antes de atingir o litoral catarinense.

$\mathrm{O}$ evento de alta energia registrado em setembro/2000 causou efeitos distintos nas praias estudadas, sendo que a remobilização sedimentar foi bem mais intensa no extremo refletivo, onde detectou-se erosão de parte significativa do perfil e decréscimo pronunciado no volume de sedimento da porção subaérea da praia. Por outro lado, a magnitude da remobilização sedimentar diminuiu para o extremo dissipativo, onde alterações na morfologia praial e no volume de sedimento praticamente não foram verificadas.

Short (1980) observou que a energia de onda necessária para causar erosão praial é dependente do estágio morfodinâmico. Enquanto em praias refletivas qualquer elevação na energia de onda pode desencadear processos erosivos, no extremo dissipativo uma quantidade muito maior de energia é necessária. Assim, o comportamento diferenciado das praias estudadas frente ao evento extremo decorreu da vulnerabilidade de cada estágio morfodinâmico ao incremento da energia de onda experimentado naquela ocasião.

Com relação as variações temporais da morfologia praial, cabe ainda destacar que o acréscimo pronunciado no volume de sedimento verificado para a praia de Taquaras em outubro/2000 constituiu uma resposta particular desta praia a alterações na direção predominante de onda ocorridas no período (Benedet Filho, 2000; Klein et al., 2002).

A praia de Taquaras situa-se em uma enseada aberta para o mar juntamente com a praia de Taquarinhas. Esta última localiza-se ao norte da praia de Taquaras, sendo separada desta por um promontório rochoso que se estende cerca de $10 \mathrm{~m}$ em direção ao mar (Klein et al., 2002). Estudando a morfodinâmica de praias de enseada com ênfase na análise da movimentação lateral de sedimentos, Benedet Filho (2000) e Klein et al. (2002) verificaram que inversões no sentido predominante da deriva litorânea e, portanto, no padrão de transporte lateral de sedimentos ocorrem entre as extremidades desta enseada como resultado de alterações na direção predominante de onda.

Em setembro/2000, Benedet Filho (2000) e Klein et al. (2002) observaram uma pronunciada erosão na porção subaérea da praia de Taquarinhas em resposta ao evento extremo registrado nesta ocasião. Estes autores verificaram ainda uma forte dominância de ondas do quadrante norte durante os meses de setembro e outubro/2000. Assim, a pronunciada acresção verificada neste estudo, e por Benedet Filho (2000) e Klein et al. (2002), na porção central da praia de Taquaras, em outubro/2000, deve ter decorrido da migração dos sedimentos erodidos de Taquarinhas para aquela praia. A ausência de novos eventos erosivos extremos e/ou a persistência de ondas do quadrante NE devem ter contribuído para a manutenção do volume expressivo de sedimento verificado na porção subaérea da praia de Taquaras até o final deste estudo.

Uma relação entre o estágio morfodinâmico das praias e a variabilidade tem- 
poral no tamanho médio e seleção do sedimento foi observado neste estudo, sendo que a magnitude destas variações aumentou do extremo dissipativo para o refletivo. Tal fato constituiu, provavelmente, um reflexo do comportamento dinâmico destas praias, sendo que o incremento na variabilidade das características sedimentares para o extremo refletivo esteve associado à intensificação do retrabalhamento dos depósitos sedimentares aí existentes. O mesmo se aplica ao incremento da magnitude das variações sedimentares observadas no sentido terra-mar em Taquaras, o qual decorreu, provavelmente, do retrabalhamento mais intenso nos níveis inferiores desta praia como salientado anteriormente.

A redução no teor de umidade do sedimento e o incremento da profundidade do lençol freático do extremo dissipativo para o refletivo observados neste estudo, foram também verificados por outros autores (Jaramillo et al., 1993; Jaramillo, 1994; Giménez \& Yannicelli, 1997) e decorreram das diferentes feições sedimentares e morfológicas das praias estudadas.

O gradiente de profundidade do lençol freático na direção do pós-praia foi muito mais pronunciado na praia de Taquaras como resultado da inclinação acentuada de seu perfil, e decresceu para a praia de Navegantes onde a inclinação praial foi suave. Por outro lado, as maiores variações temporais na salinidade do lençol freático ocorreram na praia de Navegantes onde se verificou igualmente os gradientes mais intensos de salinidade ao longo do perfil. Embora outros fatores capazes de influenciar a salinidade do lençol não tenham sido obtidos durante este estudo (p. ex. precipitação), estes resultados devem ter decorrido, ao menos parcialmente, do fato da obtenção da salinidade na praia de Taquaras ter se restringido aos níveis próximos da água, onde foi possível ter acesso ao lençol freático.

A redução do teor de umidade do sedimento do extremo dissipativo para o refletivo resultou, provavelmente, do incremento obser- vado no mesmo sentido para a profundidade média do lençol freático e tamanho médio do sedimento, o qual retém menos água em função da maior permeabilidade. Além disso, a diminuição da declividade para o extremo dissipativo permite que os espraiamentos de onda alcancem níveis mais superiores da praia durante a maré alta umedecendo periodicamente setores mais distantes da linha d'água (próximos da linha de deposição). Em função dos níveis mais inferiores da praia de Navegantes terem permanecido geralmente próximos da saturação, as maiores variações na umidade do sedimento foram verificadas para os níveis superiores da praia.

Por outro lado, em Taquaras teores elevados de umidade ocorreram apenas na região delimitada pelo espraiamento das ondas e o gradiente de umidade do sedimento variou temporalmente de acordo com o posicionamento desta zona ao longo do perfil. Teores de umidade elevados foram verificados nos níveis mais superiores desta praia apenas durante o evento extremo ocorrido em setembro/2000, coincidindo com o deslocamento do espraiamento de ondas para o mesmo setor da praia. Ao passo que, a partir de outubro/2000, a acresção do perfil resultou no deslocamento da zona úmida para níveis inferiores da praia.

As alterações ambientais associadas com o gradiente morfodinâmico parecem ter conseqüências relevantes para a macrofauna bentônica de praias arenosas (Brazeiro, 2001). Estudos comparativos realizados em diferentes províncias geográficas têm demonstrado uma tendência de diminuição na riqueza, abundância e biomassa da macrofauna bentônica de praias dissipativas para refletivas (p. ex. Defeo et al., 1992; Jaramillo \& McLachlan, 1993; Borzone et al., 1996; McLachlan et al., 1995; Brazeiro, 2001). Entretanto, a maioria destes trabalhos não tem considerado a dinâmica temporal das características ambientais e seu efeito sobre a macrofauna bentônica.

Em Santa Catarina, a ausência de sazonalidade nas variáveis ambientais consti- 
tuiu uma característica marcante das praias estudadas, sendo que a ocorrência de eventos imprevisíveis de alta energia parecem ser responsáveis por alterações pronunciadas em determinados parâmetros. Estas praias caracterizaram-se por diferentes aspectos hidrodinâmicos, sedimentares e morfológicos, incluindo distintos gradientes verticais de umidade, profundidade e salinidade do lençol freático, tamanho e seleção de grão. Além disso, o comportamento temporal das variáveis ambientais foi particular para cada uma das praias estudadas e decorreu das características hidrodinâmicas, sedimentares e morfológicas associadas com cada estágio morfodinâmico.

Desta forma, e considerando a grande variabilidade nas características ecológicas das comunidades de praias arenosas (Brazeiro, 2001), as variações espaço-temporais nos fatores ambientais relacionadas com o espectro morfodinâmico observadas neste trabalho podem condicionar alterações na composição, abundância, biomassa e padrões de zonação da macrofauna bentônica ao longo do gradiente refletivo-dissipativo da região de estudo.

\section{AGRADECIMENTOS}

Ao Prof. Fernando Luiz Diehl, diretor do Centro de Ciências Tecnológicas, da Terra e do Mar (CTTMar) da Universidade do Vale do Itajaí (UNIVALI) no período de desenvolvimento deste trabalho, pela disponibilização de pessoal, viaturas, estrutura física e demais recursos dos laboratórios de pesquisa, os quais foram indispensáveis para a execução deste trabalho. Ao colega e técnico do CTTMar Robson de Souza pelo auxílio nas saídas de campo. Aos colegas do Laboratório de Oceanografia Geológica (CTTMar/UNIVALI), professores Antônio H. F. Klein, João T. Menezes e José Gustavo N. de Abreu e técnicos Sr. Gentil Silvestre e Marcos Paulo Birribili, pela disponibilização de equipamentos para obtenção da morfologia praial, pela estrutura física e auxílio no processamento do material sedimentológico, e pela orientação no processamento dos dados morfológicos.

\section{REFERÊNCIAS BIBLIOGRÁFICAS}

Alava, A. \& O. Defeo. 1991. Distributional pattern and population dynamics of Excirolana armata (Isopoda: Cirolanidae) in a Uruguayan sandy beach. Estuar. coast. Shelf Sci., 33: 433-444.

Alves, E.S. \& S.A. Rodrigues. 2003. Distributional patterns of Austinixa patagoniensis (Rathbun, 1918) (Decapoda: Pinnotheridae), a symbiotic crab of Callichirus major (Decapoda: Callianassidae), in Balneário Camboriú Beach, Santa Catarina, Brazil. J. Coast. Res., Proceedings of the Brazilian Symposium on Sandy Beaches: Morphodynamic, Ecology, Uses, Hazards and Management, Special Issue, 35: 408417.

Alves, J.H.G. M. \& E. Melo. 2001. Measurement and modeling of wind waves at the northern coast of Santa Catarina, Brazil. Revta. Bras. Oceanogr., 49: 13-28.

Benedet Filho, L. 2000. Morfodinâmica de praias de enseada: um estudo do comportamento dos processos de rotação praial. Monografia de Conclusão do Curso de Oceanografia, Universidade do Vale do Itajaí.

Birkemeier, W.A. 1981. Fast accurate twoperson beach survey. Coastal Engineering Technical Aid 81-11, U. S. Army Engineer Waterways Experiment Station, Coastal Engineering Research Center, Mississipi.

Birkemeier, W.A. 1986. A user's guide to ISRP: the interactive survey reduction program. Instruction report CERC-84-1, U. S. Army Engineer Waterways Experiment Station, Coastal Engineering Research Center, Mississipi.

Borzone, C.A. 1999. Influence of Mellita quinquiesperforata beds on the structure of subtidal benthic communities of sandy 
beaches. In: M.D.C. Carnevali \& F. Bonasoro (Eds.), Echinoderm Research 1998, Balkema, Rotterdeam: 433-438.

Borzone, C.A.; Souza, J.R.B. \& A.G. Soares. 1996. Morphodynamics and tropical macrofauna structure. Revta. Chilena Hist. Nat., 69(4): 565-577.

Brazeiro, A. 2001. Relationship between species richness and morphodynamics in sandy beaches: what are the underlying factors? Mar. Ecol. Prog. Ser., 224: 35-44.

Brown, A.C. \& A. McLachlan. 1990. Ecology of Sandy Shores. Elsevier.

Carvalho, J.L.B.; Klein, A.H.F.; Schettini, C.A.F. \& P. M. Jabor. 1996. Marés meteorológicas em Santa Catarina: influência do vento na determinação de parâmetros de projetos para obras costeiras. Proceedings of III Simpósio sobre Oceanografia, Universidade de São Paulo, p.380.

CERC, 1981. BMAP: Beach Morphology Analysis Package. Version 2.0. Coastal Engeenier Research Center, USA.

Defeo, O. 1996. Experimental management of an exploited sandy beach bivalve population. Revta. Chilena Hist. Nat., 69: 605-614.

Defeo, O.; Jaramillo, E. \& A. Lyonnet. 1992. Community structure and intertidal zonation of the macroinfauna on the Atlantic Coast of Uruguai. J. Coast. Res., 8(4): 830-839.

Defeo, O. \& A. Alava. 1995. Effects of human activities on long-term trends in sandy beach populations: the wedge clam Donax hanleyanus in Uruguai. Mar. Ecol. Prog. Ser., 123: 73-82.

Defeo, O. \& G. Martinez. 2003. The habitat harshness hypothesis revisited: life history of the isopod Excirolana braziliensis in sandy beaches with contrasting morphodynamics. J. Mar. Biol. Ass. U. K., 83: 331-340.

Folk, R.L. \& W.C. Ward. 1957. Brazos river bar: a study in the significance of grain size parameters. J. Sedim. Petrol., 27(1): 3-26. Giménez, L. \& B. Yannicelli. 1997. Variability of zonation patterns in temperate microtidal
Uruguayan beaches with different morphodynamic types. Mar. Ecol. Prog. Ser., 160: 197-207.

Jaramillo, E. 1994. Patterns of species richness in sandy beaches of South America. S. Afr. J. Zool., 29: 227-234.

Jaramillo, E. \& A. McLachlan. 1993. Community and population responses of the macroinfauna to physical factors over a range of exposed sandy-beaches in south-central Chile. Est. coast. Shelf Sci., 37: 615624.

Jaramillo, E.; McLachlan, A. \& P. Coetzee. 1993. Intertidal zonation patterns of macroinfauna over a range of exposed sandy beaches in south-central Chile. Mar. Ecol. Prog. Ser., 101: 105-118.

Klein, A.H.F. \& J.T. Menezes. 2001. Beach morphodynamics and profile sequence for a headland bay coast. J. Coast. Res., 17(4): 812-835.

Klein, A.H.F.; Benedet Filho, L. \& D.H. Schumacher. 2002. Short-term beach rotation processes in distinct headland bay beach systems. J. Coast. Res., 18(3): 442458.

McArdle, S. \& A. McLachlan. 1992. Sandy beach ecology: swash features relevant to the macrofauna. J. Coast. Res., 8(2): 398407.

McLachlan, A. 1990. Dissipative beaches and macrofauna communities on exposed intertidal sands. J. Coast. Res., 6(1): 5771.

McLachlan, A.; Jaramillo, E.; Defeo, O; Dugan, J.; de Ruyck, A. \& P. Coetzee. 1995. Adaptations of bivalves to different beach types. J. Exp. Mar. Biol. Ecol., 187: 147160.

Menezes, J.T. 1999. Aspectos morfodinâmicos das praias do litoral centro-norte catarinense. Monografia de Conclusão de Curso de Oceanografia, Universidade do Vale do Itajaí.

Miot da Silva, G. 2000. Estudo do padrão de distribuição dos sedimentos das praias arenosas do litoral centro-norte de Santa 
Catarina. Monografia de Conclusão de Curso de Oceanografia, Universidade do Vale do Itajaí.

Moraes, G.N. \& G.H. Griep. 1985. ANGRA, um analisador granulométrico para micros. II Encontro Brasileiro de Oceanólogos, Universidade do Rio Grande, RS, p 33.

Nobre, C.A.; Cavalcanti, M.A.G.; Nobre, P.; Kayano, M.T.; Rao, V.B.; Bonatti, J.P.; Satyamurti, P.; Uvo, C.B. \& J.C. Cohen. 1986. Aspectos da climatologia dinâmica do Brasil. Climanálise, Número especial.

Schettini, C.A.F. 2002. Caracterização física do estuário do rio Itajaí-açu, SC. Revta. Bras. Rec. Hídric., 7(1): 123-142.

Schettini, C.A.F.; Carvalho, J.L. \& E. Truccolo. 1999. Aspectos hidrodinâmicos da enseada da Armação de Itapocoroy, SC. Notas Téc. FACIMAR, 3: 99-109.

Short, A.D. 1980. Beach response to variations in breaker height. Proceedings of $17^{\text {th }}$ International Conference of Coastal Engineering, ASCE, Sydney, Australia, Chapter 63: 1016-1035.
Short, A. 1999. Handbook of beach and shoreface morphodynamics. John Wiley \& Sons.

Temme, B.; Klein, A.H.F.; Carvalho, J.L.B. \& F.L. Diehl. 1997. Morphologic behaviour of Balneário Camboriú beach, Santa Catarina - Brazil: preliminary results. Notas Téc. FACIMAR, 1: 49-65.

Truccolo, E.C. 1998. Maré meteorológica e forçantes atmosféricas locais em São Francisco do Sul -SC. Dissertação de Mestrado em Engenharia Ambiental, Universidade Federal de Santa Catarina.

Villwock, J.A. 1987. Processos costeiros e a formação das praias arenosas e campos de dunas ao longo da costa sul e sudeste brasileira. Publ. ACIESP, 54(1): 380-398.

Wright, D. \& A.D. Short. 1984. Morphodynamic variability of surf zones and beaches: synthesis. Mar. Geol., 56: 93-118.

Zar, J. H. 1996. Biostatistical analysis, $3^{\text {th }}$ Ed. Prentice Hall. 